\title{
Alleviation of Salinity and Metal Stress Using Plant Growth-Promoting Rhizobacteria Isolated From Semiarid Moroccan Copper-Mine Soils
}

\author{
Atika Madline \\ Universite Cadi Ayyad Faculte des Sciences et Techniques Gueliz \\ Leila Benidire \\ Universite Cadi Ayyad Faculte des Sciences et Techniques Gueliz \\ Ali Boularbah ( $\square$ aliboularbah@yahoo.fr) \\ Faculté des Sciences et Techniques de Marrakech
}

\section{Research Article}

Keywords: Mine tailings, Heavy metal, Salinity, PGPR, Bioinoculants, Root elongation

Posted Date: April 19th, 2021

DOI: https://doi.org/10.21203/rs.3.rs-381425/v1

License: (a) (1) This work is licensed under a Creative Commons Attribution 4.0 International License. Read Full License

Version of Record: A version of this preprint was published at Environmental Science and Pollution Research on July 10th, 2021. See the published version at https://doi.org/10.1007/s11356-021-15168-8. 


\section{Abstract}

Phytoremediation is an eco-friendly method for rehabilitation of mine tailing using plants and their associated rhizosphere microorganisms. Some heavy metal and salt-tolerant plant growth promoting rhizobacteria (PGPR) could be beneficial in alleviating soil salinity and heavy metal stress. The aim of this work is to select PGPR that could be used in phytoremediation process. Twenty-nine rhizobacteria were examined for their ability to grow at increasing concentrations of $\mathrm{NaCl}$ and high concentrations of $\mathrm{Zn}, \mathrm{Pb}, \mathrm{Cu}$ and $\mathrm{Cd}$. The results showed that seventeen rhizobacteria displayed high salinity and metal tolerance (up to $100 \mathrm{~g} \mathrm{~L}^{-1} \mathrm{NaCl}$, up to $5 \mathrm{mM} \mathrm{Cd}, 9 \mathrm{mM} \mathrm{Pb}, 10 \mathrm{mM} \mathrm{Zn}$, and Cu up to $6 \mathrm{mM}$ ). This work showed also that salinity and metallic stress has affected bacterial growth and metabolism by increasing intracellular proline, soluble sugars, free amino-acids and exopolysaccharides production. Moreover, almost all tested bacteria maintained their PGP traits under $10 \%$ of $\mathrm{NaCl}$ and multi-metal stress. Four strains exhibiting the best PGP activities namely Mesorhizobium tamadayense, Enterobacter xiangfangensis, Pseudomonas azotifigens and Streptomyces Caelestis were selected for root elongation bioassay. The consortium of these rhizobacteria improves significantly the root elongation of Peganum harmala and Lactuca sativa under metallic and salt stress. Thus, the rhizobacteria with beneficial traits as well as tolerance to abiotic stress could be useful to stimulate plants establishment under different environmental stresses.

\section{Introduction}

Rapid population growth and increase in urbanization relies strongly on mining activities and industrial sector in order to produce commercial materials (Kabata-Pendias and Pendias, 2001). These activities involve several steps releasing different wastes, which may contain significant amounts of toxic contaminants that can pollute the air, soil, water and could affect negatively flora and fauna (El Khalil et al. 2008; El Hamiani et al. 2010). Moreover, due to their high toxicity and persistence within the environment, heavy metals are one of the major pollutants of the concern to human health (Adriano 2001). Once accumulated in soil, the toxic metals are transferred by roots to different plant parts. Consequently, they can be accumulated in the human body through food webs, causing chronic and acute disorders and leads to serious health problems afterwards (Boularbah et al. 2006a, b; El Khalil et al. 2008; El Amari et al. 2014; El Hamiani et al. 2015). Furthermore, for sensitive plants, high level of these contaminants is extremely toxic. Indeed, high concentrations of heavy metal in soil can lead to several adverse damages in plants root system, membrane permeability and photosynthesis process resulting in restricting of plant growth and lead to decrease of yield and quality of crop (Prabu 2009; Rizvi and Khan 2018). In addition, several studies indicated that high level of heavy metals had various impacts on soil microbial composition and functional diversity (Boularbah et al. 1992; Benidire et al. 2016; Alam et al. 2019; Lin et al. 2019; Liu at al. 2019; Jiang et al. 2019).

Strong efforts have been made to develop an eco-friendly and cheaper technique for the restoration of heavy metals degraded soils and preventing the spread of contaminants through wind and/or water erosion. In opposition to physico-chemical technologies that interfere with the soil structure, phytostabilization is one of the most environmentally-friendly technologies used to decrease metal bioavailability in soil and reduce their toxicity (Cunningham and Berti 2000; Conesa et al. 2007, Craw et al. 2007; Zou et al. 2012; Testiati et al. 2013; Shackira 2017 a, b). However, plants growing in metal polluted soils encounter usually adverse growth due to edaphic and climatic factors, such as drought and salinity, which limit plant growth, biomass production, and thus influence the efficiency of the phytoremediation process (Pavel et al. 2014; Cui et al. 2020). Nevertheless, the use of plants growth promotion rhizobacteria (PGPR) may be a promising solution to overcome these problems. Indeed, it has already been demonstrated that the application of metal-tolerate PGPR may decrease the availability of the metal contaminants and promote plant growth under stressed conditions (Dary et al. 2010; Ma et al. 2016; Benidire et al. 2020). A wide range of abiotic stress tolerant bacteria can confers adaptive benefit to their host plant against various stress, such as heavy metals, drought and salt through various mechanisms; including the production of plant growth promoting (PGP) substances like phytohormones (gibberellic acid, cytokinins, and indole-3-acetic acid (IAA)); stress-alleviating enzyme such as 1-aminocyclopropane-1-carboxylate (ACC) deaminase, and other traits which can improve plant nutrition (e.g. siderophores production), as well as solubilization of non-available phosphorus (Sandhya et al. 2010; Benidire et al. 2016; Ma et al. 2016; Vurukonda et al. 2016; Román-ponce et al. 2017). In addition, it has been recently reported that improving population density of osmo-tolerant rhizobacteria in the root zone can significantly decrease the content of $\mathrm{Na}^{+}$ions via binding these cations through exopolysaccharides production leading to the decrease ofavailable $\mathrm{Na}^{+}$for plant uptake and alleviate salt stress in plants grown under salt condition (Upadhyay et al. 2011; Zhu et al. 2018; Din et al. 2019). Therefore, improving plant-PGPR interactions can enhance plants biomass production under environmental stresses (e.g. salinity, drought and metal stresses), immobilization of HMs and consequently leading to the success of the phytoremediation strategy.

Recently, PGPR have been widely used as an efficient biofertilizer to increase crop productivity especially under stressed environment (Ibiene et al. 2012; Egamberdieva et al. 2016; Coniglio et al. 2019). However, there is limited information about the effect of stress on PGP traits and few works were focused on the physiological mechanisms and adaptation strategies used by the PGPR to overcome the stressed conditions (e.g.drought, salinity and metal stress) (Sandhya et al. 2010; Chakraborty el al. 2013; Upadhyay et al. 2011; Ma et al. 2016).

The objectives of this study were: (1) to screen rhizobacteria for their tolerance to high levels of salt, drought and metal stress; (2) to understand adaptive mechanisms used by rhizobacteria to overcome salinity and heavy metal stress; (3) evaluate the effect of abiotic stress on PGP traits of the studied strains and (4) finally assess the effect of heavy metal and osmo-tolerant PGPR on seedling growth under osmotic and metallic stress.

\section{Material And Methods}

\subsection{Screening of plant growth-promoting rhizobacteria for their abiotic stress tolerance}


Twenty-nine rhizobacteria, previously isolated from the rhizosphere of some metallophytes species growing on metal contaminated soils of a former copper mine site located at $35 \mathrm{~km}$ of Marrakech city-Morocco (Benidire et al. 2016), were used for this study. Bacterial strains were screened for their ability to tolerate osmotic and heavy metal stress as described below.

\subsubsection{Bacterial growth studies under increasing levels of $\mathrm{NaCl}$}

Bacterial salt stress tolerance was tested on nutrient broth medium supplemented with five different concentrations of sodium chloride (NaCl): $20,40,60,80$ and $100 \mathrm{~g} \mathrm{~L}^{-1}$. Bacteria cultures were incubated at $28^{\circ} \mathrm{C}$ for 6 days under shaking conditions. Positive strains growth was confirmed by measuring optical density at $600 \mathrm{~nm}$. Viable cells were estimated by appearance of recongnizable individual colonies in the trypticase soy agar (TSA) plates after plating 100 $\mu \mathrm{L}$ of bacterial suspension from each treatment on the surface of TSA. For this test, medium containing only the bacterial strains was used as a control. The experiment was conducted in triplicate.

\subsubsection{Metal resistance test}

The effect of metals on PGPR strains was tested by inoculating each bacteria in LB broth supplemented with different concentrations of single and multimetal solutions as follows: $\mathrm{Cu}$ at 3, 6, 7, and $8 \mathrm{mmol} \mathrm{L}^{-1}$ as $\mathrm{CuSO}_{4} ; \mathrm{Zn}$ at 3, 5, 10, and $15 \mathrm{mmolL}^{-1}$ as $\mathrm{ZnSO}_{4} ; \mathrm{Pb}^{2}$ at 3, 6, 9, and $12 \mathrm{mmol} \mathrm{L}^{-1}$ as $\left.\mathrm{Pb}_{(\mathrm{NO}}\right)_{2}$; $\mathrm{Cd}$ at 2,3, 4, 5 and 6 mmol. $\mathrm{L}^{-1}$ as $\mathrm{Cd}\left(\mathrm{NO}_{3}\right)$ and mixed-metal solutions of $\mathrm{CuSO}_{4} / \mathrm{ZnSO}_{4} / \mathrm{Pb}\left(\mathrm{NO}_{3}\right)_{2} / \mathrm{Cd}\left(\mathrm{NO}_{3}\right)$ at $0.2,0.5,1$ and 2 mmol L ${ }^{-1}$. The cultures were kept on rotary shaker for $48 \mathrm{~h}$ at $28^{\circ} \mathrm{C}$ and $150 \mathrm{rpm}$. The viability of bacteria exposed to metals stress was checked using the triphenyltetrazolium chloride (TTC) test as described by Pandey and Bhatt (2015). A positive metal tolerance test is indicated by the appearance of a red color in the tube after the addition of TTC. Bacterial cultures in LB medium not supplemented with metal salts were used as a control. The experiments were carried out in triplicate.

\subsection{Evaluation of PGP activities of osmotolerant strains under salt and metallic stress}

Seventeen PGPR strains, able to tolerate the highest levels of osmotic stress (up to $100 \mathrm{~g} \mathrm{~L}^{-1}$ of NaCl), were chosen to test their PGP traits under $10 \%$ of $\mathrm{NaCl}$ and under mixed-metal solution of $\mathrm{CuSO}_{4} / \mathrm{ZnSO}_{4} / \mathrm{Pb}\left(\mathrm{NO}_{3}\right)_{2} / \mathrm{Cd}\left(\mathrm{NO}_{3}\right)$ at $0.5 \mathrm{mM}$ for each metal.

The effect of salt and metallic stress on phosphate solubilization ability of rhizobacterial strains was evaluated in the National Botanical Research Institute's phosphate growth medium (NBRIP) (Nautyial 1999; Tripura et al. 2007; Singh et al. 2015) amended with $0.5 \%$ of tricalcium phosphate and $10 \%$ of NaCl or $0.5 \mathrm{mM}$ of mixed-metal solutions. Triplicate $100-\mathrm{mL}$ Erlenmeyer flasks containing $40 \mathrm{ml}$ of NaCl-NBRIP medium were inoculated with $1 \mathrm{~mL}$ of fresh bacterial suspension with optical density of 0.5 at $600 \mathrm{~nm}$ equivalents to $310^{8} \mathrm{CFU} \mathrm{mL}{ }^{-1}$. NBRIP media without $\mathrm{NaCl}$ or mixed-metal solution were used as acontrol. The flasks were incubated at $28^{\circ} \mathrm{C}$ for 5 days under constant agitation at $130 \mathrm{rpm}$. Supernatants of the bacterial cultures were collected by centrifugation at $10000 \mathrm{rpm}$ for $10 \mathrm{~min}$ and were used for quantitative estimation of available phosphorus by the Olsen method (Watanabe and Olsen 1965).

To assess the effect of salt and metallic stress on siderophores production, Chrome Azurol (CAS) broth medium was prepared according to Schwy and Neilands (1987) and was amended with $10 \%$ of $\mathrm{NaCl}$ or the mixture of four metals ( $\mathrm{Cu}, \mathrm{Pb}, \mathrm{Zn}$ and $\mathrm{Cd}$ ) at 0.5 mM. The modified medium was inoculated with $100 \mu \mathrm{L}$ of fresh bacterial culture and incubated at $28^{\circ} \mathrm{C}$ for 5 days under shaking condition at $130 \mathrm{rpm}$. Non-amended CAS medium was used as control. The development of yellow-orange color was considered as a positive result for siderophores production. The efficiency of siderophores production by bacterial strains under stress was estimated by comparing color intensity on the modified CAS medium with unmodified control by measuring absorbance at $630 \mathrm{~nm}$ by UV spectrophotometer.

Ammonia production was estimated according to Cappucino and Sherman (1992). Bacterial strains were inoculated in peptone solutionamendedwith10\% of $\mathrm{NaCl}$ or the mixture of four metals $(\mathrm{Cu}, \mathrm{Pb}, \mathrm{Cd}$ and $\mathrm{Zn})$ at $0.5 \mathrm{mM}$ and incubated at $28^{\circ} \mathrm{C}$. After 5 days of incubation, a volume of $500 \mu \mathrm{L}$ of Nessler's reagent was added to each tube. Development of a brown to yellow color on the bacterial culture was considered as positive test for ammonia production. Bacterial cells incubated in non-modified peptone solution were used as a control.

PGPR strains were also screened for their ability to produce indol-3-acetic acid (IAA) according to Gordon and Weber (1951) under salt (10\% of NaCl) and metallic stress (the mixture of four metals $(\mathrm{Cu}, \mathrm{Pb}, \mathrm{Cd}$ and $\mathrm{Zn}$ at $0.5 \mathrm{mM})$. Fresh cultures were cultivated in LB broth supplemented with $1 \% \mathrm{~L}$-tryptophan $(5$ $\mathrm{mM}$ ) and $10 \%$ of $\mathrm{NaCl}$ or multi-metal solution for 5 days at $28^{\circ} \mathrm{C}$. Medium added with only $0.5 \%$ of $\mathrm{NaCl}$ as usual concentration was used as control. After incubation, $1 \mathrm{~mL}$ of the supernatant obtained by centrifugation at $10000 \mathrm{rpm}$ for $10 \mathrm{~min}$ was mixed with $2 \mathrm{~mL}$ of Salper reagent $(2 \%$ of $0.5 \mathrm{M} \mathrm{FeCl} 3$ in $35 \%$ $\mathrm{HClO}_{4}$ solution) and kept in the dark for30 min. The optical density of the extracted sample and standard IAA were measured at $530 \mathrm{~nm}$. For each strain, the experiment was carried out in replicate.

\subsection{Bacterial response to osmotic and metallic stress}

\subsubsection{Exopolysaccharides production}

The ability of bacterial strains to produce exopolysaccharides (EPS) was assessed both in the presence and in absence of salt (10 $\mathrm{g} \mathrm{L}{ }^{-1}$ ) and metallic stress (the mixture of $\mathrm{Cu}, \mathrm{Pb}, \mathrm{Cd}$ and $\mathrm{Zn}$ at $0.5 \mathrm{mM}$ ). A quantitative determination of EPS production was performed as described by $\mathrm{Ghafoor}$ et al, (2011) with few modifications. Briefly, a volume of $1 \mathrm{~mL}$ of supernatant, obtained from rhizobacterial cultures grown in non-amended LB and in LB supplemented with NaCl $(10 \%)$ or multi-metal solution for 5 days at $28^{\circ} \mathrm{C}$, was mixed with $1 \mathrm{~mL}$ of $2 \%(\mathrm{w} / \mathrm{v})$ Congo Red solution and incubated under shaking (120 rpm) for $120 \mathrm{~min}$ at $28^{\circ} \mathrm{C}$. Bacterial cells and bound Congo Red were precipitated by centrifugation at $10000 \mathrm{rpm}$ for $5 \mathrm{~min}$. The supernatant was then collected and its optical density was measured at $490 \mathrm{~nm}$. The amount of EPS produced was estimated by determining the total percentage of free Congo Red remaining in the supernatant. 


\subsubsection{Free amino acids production}

Free amino acids were determined spectrophotometrically by using the Ninhydrin method as described by Ondobo et al. (2017). The bacterial cells were grown for 5 days at $28^{\circ} \mathrm{C}$ in non-stressed and stressed nutrient broth media with a mixture of four metals $(\mathrm{Cu}, \mathrm{Pb}, \mathrm{Cd}$ and $\mathrm{Zn})$ at $0.5 \mathrm{mMand} 10 \%$ of $\mathrm{NaCl}$, respectively. The bacterial pellets obtained after centrifugation of cultures at $10000 \mathrm{rpm}$ for $10 \mathrm{~min}$, were boiled in a water bath at $60^{\circ} \mathrm{C}$ for $45 \mathrm{~min}$ in the presence of $80 \%$ methanol. The resulting extract was then centrifuged and the amino acids content was estimated in the supernatant by measuring its absorbance at $570 \mathrm{~nm}$. A pure analytical grade glycine was used as a standard curve at concentrations of $25,50,100 \mathrm{and} 150 \mu \mathrm{mol} \mathrm{mL}^{-1}$.

\subsubsection{Proline production}

Accumulation of proline was analyzed spectrophotometrically following the method described by Bates et al. (1973) with slight modifications. Briefly, bacterial cells obtained by centrifugation of 5 days culture grown in nutrient broth supplemented or not with $10 \%$ of $\mathrm{NaCl}$ or mixed-metal solution (same concentration as used above), was mixed with ninhydrinin glacial acetic acid for $1 \mathrm{~h}$ at $100^{\circ} \mathrm{C}$ and then the tubes were placed in an ice bath to stop the reaction. Subsequently, proline content was extracted by adding toluene and the absorbance was measured at $520 \mathrm{~nm}$. The experiment was repeated three times. The proline concentration was determined using a calibration curve of pure proline as a standard at concentrations of $50,100,150,200,250 \mu \mathrm{gL}-1$

\subsubsection{Soluble sugars accumulation}

Total sugars content was determined on non-stressed $(0.5 \% \mathrm{NaCl})$ and stressed $(10 \% \mathrm{NaCl}$, and mixed-metal solution) cultures according to the procedure described by Dubois et al. (1956). The pellet of bacterial cell culture was mixed with methanol-chloroform (4:1) solution and boiled in water bath at $60^{\circ} \mathrm{C}$ for $20 \mathrm{~min}$. The obtained supernatant was then treated with phenol (5\%) and sulfuric acid (98\%). The absorbance of the mixture was read at $485 \mathrm{~nm}$ after 20 min of incubation at $100^{\circ} \mathrm{C}$. A standard curve was prepared with known concentrations of glucose at concentrations of $25,50,100,150,200 \mu \mathrm{gL}-1$.

\subsubsection{Proteins contents}

The protein content of bacterial cells was determined by using Bradford method (1976). Pellets, obtained by centrifugation of bacterial cultures grown in nonstressed and salt $(10 \% \mathrm{NaCl})$ or multi-metal stressed LB medium, were washed vigorously with $\mathrm{MgSO}_{4}(10 \mathrm{mM})$ and resuspended in $500 \mu \mathrm{L}$ of phosphate buffer ( $\mathrm{pH}$ 6.8). The extract was kept for $30 \mathrm{~min}$ at room temperature. Finally, proteins concentration in supernatant was determined by reading the absorbance at $595 \mathrm{~nm}$ and using bovine serum albumin as a standard working solution.

\subsection{Effect of selected PGPR strains on seedling shoot and root growth under salt and metallic stress}

\subsubsection{Bacterial inoculant preparation}

In order to evaluate the effect of PGPR on seed germination and plant root elongation, four bacterial strains were chosen for this assay: Mesorhizobium tamadayense BKM 04, Enterobacter xiangfangensis BKM 30, Pseudomonas azotifigens BKM 07 and Streptomyces Caelestis BKM 05.These bacteria were chosen based on their ability to tolerate high level of abiotic stress and their ability to maintain high level of PGP activities under salt stress. To test that there is no antagonistic activity between the chosen strains, plate confrontation tests were performed in TSA medium (Upadhyay et al. 2011). For this reason, $1 \mathrm{~mL}$ of a bacterial culture was spread evenly over the surface of Petri plates prepared with TSA. Then, another bacterial culture was spotted on the bed of the first one. The resulting plates were incubated at $28^{\circ} \mathrm{C}$ for $48 \mathrm{~h}$. The absence of clear bacteria-free zone around the spotted cultures indicated the absence of an antagonistic effect between the two tested rhizobacteria.

For the germination test, the bacterial inoculant was prepared as described by Whiting et al. (2001). Each rhizobacteria was grown on nutrient broth medium for $24 \mathrm{~h}$ at $28^{\circ} \mathrm{C}$, centrifuged at $10000 \mathrm{rpm}$ for $10 \mathrm{~min}$, washed twice with a sterile saline solution ( $0.9 \%$ (w:v) $\left.\mathrm{NaCl}\right)$ and then resuspended in $1 \%$ of

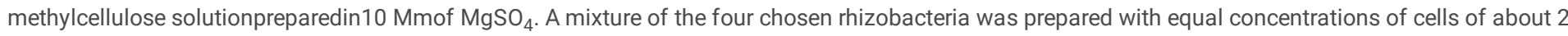
$10^{8} \mathrm{UFC} \mathrm{mL}^{-1}\left(\mathrm{DO}_{600}=0,8\right)$. A sterile methylcellulose non-inoculated with bacteria was used as control.

\subsubsection{Seeds treatments and growth conditions}

Two species were used in this study, seeds of Peganum harmala L. (wild rue) collected from Kettara mine area used as native species and seeds of Lactuca sativa L. (lettuce) from Sogemag Company used as sensitive species. Both species seeds were surface sterilized with 70 \% ethanol followed by $3 \%$ sodium hypochlorite for $5 \mathrm{~min}$ and successively washed several times with deionized sterilized water. The surface-sterilized seeds were then soaked in both inoculated and non-inoculated methylcellulose solutions for $30 \mathrm{~min}$.

Ten seeds of each plant species were placed in $50 \mathrm{ml}$ polyethylene tubes filled with $20 \mathrm{~mL}$ of autoclaved water-agar medium, composed of(per liter): $1.2 \mathrm{mM}$ $\mathrm{K}_{2} \mathrm{HPO}_{4}, 0.4 \mathrm{mM} \mathrm{KH}_{2} \mathrm{PO}_{4}, 5 \mathrm{mM} \mathrm{CaCl}_{2}, 3.35 \mathrm{mg}$ ferric citrate, $2.5 \mathrm{Mm} \mathrm{MgSO}_{4}, 2.5 \mathrm{mM} \mathrm{K}_{2} \mathrm{SO}_{4}, 10 \mu \mathrm{M} \mathrm{MnSO}_{4}, 20 \mu \mathrm{M} \mathrm{H} \mathrm{BO}_{3}, 5 \mu \mathrm{MZnSO}_{4}, 0.2 \mu \mathrm{M} \mathrm{CuSO}, 1.5 \mu \mathrm{M}$ $\mathrm{CaSO}_{4}, 1.0 \mu \mathrm{M} \mathrm{NaMoO}_{4}$ and $0.8 \%$ agar with pH 6.8 (Arora et al. 2012; Tewari and Arora 2014; Román-Ponce et al. 2017).The effect of PGPR on seeds germination under salt stress was evaluated in water-agar medium supplemented with $\mathrm{NaCl}$ ranging from 25 to $125 \mathrm{mM}$. To assess strains effect on seed germination under metallic stress, the plant growth medium was supplemented with different concentrations of $\left.\mathrm{Cu}\left(\mathrm{CuSO} \mathrm{S}_{4}, 5 \mathrm{H}_{2} \mathrm{O}\right), \mathrm{Pb}_{(\mathrm{Pb}}\left(\mathrm{NO}_{3}\right)_{2}\right)$ and $\mathrm{Cd}$ $\left(\mathrm{Cd}\left(\mathrm{NO}_{3}\right)_{2}\right.$ ranging from 0.06 to $1 \mathrm{mM}$ for each metal and $\mathrm{Zn}\left(\mathrm{ZnSO}_{4}, 7 \mathrm{H}_{2} \mathrm{O}\right)$ ranging from 0.25 to $2 \mathrm{Mm}$. Seeds placed in tubes with medium containing neither salt nor metal were used as a control. All tubes were incubated at $22^{\circ} \mathrm{C}$ for two weeks and then the length of roots and shoots was measured for 4 seedlings in each treatment. The experiment was conducted in four replicates for each treatment.

Page $4 / 21$ 


\subsection{Statistical analysis}

A one-way ANOVA with post-hoc Student Newman-Keuls test $(\mathrm{p}<0.05)$, carried out with the SPSS program (IBM, Armonk, NY, USA, version 25.0.), was used to examine the statistical difference between the results. Student's T-test was used to compare root and shoot length between inoculated seedlings and uninoculated control seedlings.

\section{Results}

\subsection{Screening of rhizobacteria for osmotic and metallic stress tolerance}

Results of the tolerance of rhizobacterial strains to salt stress are shown in Table 1 . Out of 29 tested bacteria, only 20 showed tolerance to $80 \mathrm{~g} \mathrm{~L}{ }^{-1}$ of $\mathrm{NaCl}$, 17 tolerates salt stress up to $100 \mathrm{~g} \mathrm{~L}^{-1} \mathrm{NaCl}$. Metal tolerance results of PGPR strains are shown in Table 2. All bacterial strains showed a high level of tolerance to high concentrations of heavy metals. Indeed, more than $70 \%$ of the strains were able to tolerate $\mathrm{Cu}$ up to $7 \mathrm{mM}$, about $48 \%$ tolerate $\mathrm{Pb}$ up to9mM, $25 \%$ could grow in medium with $\mathrm{Zn}$ up to $15 \mathrm{mM}$ and only $15 \%$ were able to tolerate Cd concentrations at 6 mM. However, more than $60 \%$ of the strains were able to grow well in the presence of the mixture of four metals ( $\mathrm{Zn}, \mathrm{Cu}, \mathrm{Cd}$ and $\mathrm{Pb}$ ) at $2 \mathrm{mM}$ for each metal, while only $29 \%$ could grow in medium amended with $3 \mathrm{mM}$ of the mixture tested metals. Finally, the general order of the toxic effect of metals on these bacteria was classified as following $\mathrm{Cd}>\mathrm{Cu}>\mathrm{Pb}>\mathrm{Zn}$. 
Table 1

Rhizobacterial response to different levels of $\mathrm{NaCl}$

\begin{tabular}{|c|c|c|c|c|c|c|}
\hline \multirow[t]{2}{*}{ Strains } & & \multicolumn{5}{|c|}{$\mathrm{NaCl}\left(\mathrm{g} \mathrm{L}^{-1}\right)$} \\
\hline & & 20 & 40 & 60 & 80 & 100 \\
\hline Advenella kashmerensis & BKM 01 & + & + & + & + & - \\
\hline Streptomyces enissocaesilis & BKM 02 & + & + & + & + & - \\
\hline Pseudomonas xanthomarina & BKM 03 & + & + & + & - & - \\
\hline Mesorhizobium tamadayense & BKM 04 & + & + & + & + & + \\
\hline Streptomyces caelestis & BKM 05 & + & + & + & + & + \\
\hline Bacillus subtilis & BKM 06 & + & + & + & + & + \\
\hline Pseudomonas azotifigens & BKM 07 & + & + & + & + & + \\
\hline Acinetobacter junii & BKM 08 & + & + & + & - & - \\
\hline Streptomyces caelestis & BKM 09 & + & + & + & - & - \\
\hline Pseudomonas frederiksbergensis & BKM 10 & + & + & + & + & + \\
\hline Massiliacon sociata & BKM 11 & + & + & + & - & - \\
\hline Pseudomonas frederiksbergensis & BKM 13 & + & + & + & - & - \\
\hline Pseudomonas frederiksbergensis & BKM 14 & + & + & + & + & + \\
\hline Advenella kashmerensis & BKM 20 & + & + & + & + & + \\
\hline Variovorax paradoxus & BKM 21 & + & + & + & + & + \\
\hline Pseudomonas luteola & BKM 22 & + & + & + & + & + \\
\hline Pseudomonas luteola & BKM 23 & + & + & + & + & + \\
\hline Pseudomonas frederiksbergensis & BKM 24 & + & + & + & + & - \\
\hline Pseudomonas frederiksbergensis & BKM 25 & + & + & + & - & - \\
\hline Bacillus subtilis subsp. inaquosorum & BKM 26 & + & + & + & + & + \\
\hline Enterobacter hormaechei & BKM 27 & + & + & + & + & + \\
\hline Ciceribacter lividus & BKM 28 & + & + & + & + & + \\
\hline Enterobacter hormaechei & BKM 30 & + & + & + & + & + \\
\hline Staphylococcus warneri & BKM 31 & + & + & + & - & - \\
\hline Paenibacillus hainanensis & BKM 32 & + & + & + & - & - \\
\hline Pseudomonas koreensis & BKM 33 & + & + & + & + & + \\
\hline Advenella kashmerensis & BKM 19 & + & + & + & + & + \\
\hline Bacillus aryabhattai & BKM 34 & + & + & + & - & - \\
\hline Pseudomonas frederiksbergensis & BKM 18 & + & + & + & + & + \\
\hline
\end{tabular}


Table 2

Response of different rhizobacteria to different concentration of $\mathrm{Zn}, \mathrm{Pb}, \mathrm{Cd}$ and $\mathrm{Cu}$ and to the mixture of four metals at different concentrations

\begin{tabular}{|c|c|c|c|c|c|c|c|c|c|c|c|c|c|c|c|c|c|c|c|c|c|c|c|}
\hline \multirow[t]{2}{*}{ Strains } & & \multicolumn{4}{|c|}{$\mathrm{Zn}(\mathrm{mM})$} & \multicolumn{4}{|c|}{$\mathrm{Pb}(\mathrm{mM})$} & \multicolumn{5}{|c|}{$\mathrm{Cd}(\mathrm{mM})$} & \multicolumn{4}{|c|}{$\mathrm{Cu}(\mathrm{mM})$} & \multicolumn{5}{|c|}{$\begin{array}{l}\text { Mixture of } 4 \text { metals } \\
(\mathrm{mM})\end{array}$} \\
\hline & & 3 & 5 & 10 & 15 & 3 & 6 & 9 & 12 & 2 & 3 & 4 & 5 & 6 & 3 & 5 & 6 & 7 & 0.2 & 0.5 & 1 & 2 & 3 \\
\hline $\begin{array}{l}\text { Advenella } \\
\text { kashmerensis }\end{array}$ & $\begin{array}{l}\text { BKM } \\
01\end{array}$ & + & + & + & - & + & + & + & - & + & + & + & + & - & + & + & + & + & + & + & + & + & - \\
\hline $\begin{array}{l}\text { Streptomyces } \\
\text { enissocaesilis }\end{array}$ & $\begin{array}{l}\text { BKM } \\
02\end{array}$ & + & + & + & - & + & + & + & - & + & - & - & - & - & + & + & - & - & + & + & + & + & - \\
\hline $\begin{array}{l}\text { Pseudomonas } \\
\text { xanthomarina }\end{array}$ & $\begin{array}{l}\text { BKM } \\
03\end{array}$ & + & + & - & - & + & + & + & - & + & - & - & - & - & + & + & + & + & + & + & + & + & - \\
\hline $\begin{array}{l}\text { Mesorhizobium } \\
\text { tamadayense }\end{array}$ & $\begin{array}{l}\text { BKM } \\
04\end{array}$ & + & + & + & - & + & + & + & - & + & + & - & - & - & + & + & - & - & + & + & + & + & - \\
\hline $\begin{array}{l}\text { Streptomyces } \\
\text { caelestis }\end{array}$ & $\begin{array}{l}\text { BKM } \\
05\end{array}$ & + & + & + & - & + & + & + & + & + & + & + & - & - & + & + & + & + & + & + & + & + & + \\
\hline Bacillus subtilis & $\begin{array}{l}\text { BKM } \\
06\end{array}$ & + & + & + & - & + & + & + & - & + & - & - & - & - & + & + & + & - & + & + & + & + & + \\
\hline $\begin{array}{l}\text { Pseudomonas } \\
\text { azotifigens }\end{array}$ & $\begin{array}{l}\text { BKM } \\
07\end{array}$ & + & + & - & - & + & + & - & - & - & - & - & - & - & + & - & - & - & + & + & + & - & - \\
\hline $\begin{array}{l}\text { Acinetobacter } \\
\text { junii }\end{array}$ & $\begin{array}{l}\text { BKM } \\
08\end{array}$ & + & + & + & - & + & + & - & - & + & - & - & - & - & + & + & + & + & + & + & + & + & - \\
\hline $\begin{array}{l}\text { Streptomyces } \\
\text { caelestis }\end{array}$ & $\begin{array}{l}\text { BKM } \\
09\end{array}$ & + & + & - & - & + & + & - & - & - & - & - & - & - & + & + & - & - & + & + & + & - & - \\
\hline $\begin{array}{l}\text { Pseudomonas } \\
\text { frederiksbergensis }\end{array}$ & $\begin{array}{l}\text { BKM } \\
10\end{array}$ & + & + & + & - & + & + & - & - & + & + & + & + & - & + & + & + & + & + & + & + & + & + \\
\hline $\begin{array}{l}\text { Massiliacon } \\
\text { sociata }\end{array}$ & $\begin{array}{l}\text { BKM } \\
11\end{array}$ & + & + & - & - & + & + & - & - & - & - & - & - & - & + & + & - & - & + & + & - & - & - \\
\hline $\begin{array}{l}\text { Pseudomonas } \\
\text { frederiksbergensis }\end{array}$ & $\begin{array}{l}\text { BKM } \\
13\end{array}$ & + & + & + & - & + & + & + & - & + & + & + & + & - & + & + & + & + & + & + & + & + & - \\
\hline $\begin{array}{l}\text { Pseudomonas } \\
\text { frederiksbergensis }\end{array}$ & $\begin{array}{l}\text { BKM } \\
14\end{array}$ & + & + & + & + & + & + & - & - & + & + & + & + & + & + & + & + & + & + & + & + & + & + \\
\hline $\begin{array}{l}\text { Advenella } \\
\text { kashmerensis }\end{array}$ & $\begin{array}{l}\text { BKM } \\
20\end{array}$ & + & + & + & + & + & + & - & - & + & + & + & + & + & + & + & + & + & + & + & + & + & + \\
\hline $\begin{array}{l}\text { Variovorax } \\
\text { paradoxus }\end{array}$ & $\begin{array}{l}\text { BKM } \\
21\end{array}$ & + & + & + & - & + & + & + & - & + & + & + & + & + & + & + & + & + & + & + & + & + & + \\
\hline $\begin{array}{l}\text { Pseudomonas } \\
\text { luteola }\end{array}$ & $\begin{array}{l}\text { BKM } \\
22\end{array}$ & + & + & - & - & + & + & - & - & + & - & - & - & - & + & + & + & + & + & + & - & - & - \\
\hline $\begin{array}{l}\text { Pseudomonas } \\
\text { luteola }\end{array}$ & $\begin{array}{l}\text { BKM } \\
23\end{array}$ & + & + & - & - & + & + & - & - & + & - & - & - & - & + & + & - & - & + & + & + & - & - \\
\hline $\begin{array}{l}\text { Pseudomonas } \\
\text { frederiksbergensis }\end{array}$ & $\begin{array}{l}\text { BKM } \\
24\end{array}$ & + & + & + & - & + & + & + & - & + & - & - & - & - & + & + & + & + & + & + & + & + & - \\
\hline $\begin{array}{l}\text { Pseudomonas } \\
\text { frederiksbergensis }\end{array}$ & $\begin{array}{l}\text { BKM } \\
25\end{array}$ & + & + & - & - & + & + & + & - & - & - & - & - & - & + & + & + & + & + & + & + & + & - \\
\hline $\begin{array}{l}\text { Bacillus } \\
\text { subtilissubsp. } \\
\text { inaquosorum }\end{array}$ & $\begin{array}{l}\text { BKM } \\
26\end{array}$ & + & + & - & - & + & + & + & - & - & - & - & - & - & + & + & + & + & + & + & + & - & - \\
\hline $\begin{array}{l}\text { Enterobacter } \\
\text { hormaechei }\end{array}$ & $\begin{array}{l}\text { BKM } \\
27\end{array}$ & + & + & + & + & + & + & - & - & + & - & - & - & - & + & + & + & + & + & + & + & - & - \\
\hline Ciceribacterlividus & $\begin{array}{l}\text { BKM } \\
28\end{array}$ & + & + & - & - & + & + & - & - & - & - & - & - & - & + & + & + & + & + & + & + & - & - \\
\hline $\begin{array}{l}\text { Enterobacter } \\
\text { hormaechei }\end{array}$ & $\begin{array}{l}\text { BKM } \\
30\end{array}$ & + & + & + & + & + & + & + & - & + & - & - & - & - & + & + & + & + & + & + & + & + & - \\
\hline $\begin{array}{l}\text { Staphylococcus } \\
\text { warneri }\end{array}$ & $\begin{array}{l}\text { BKM } \\
31\end{array}$ & + & + & + & + & + & + & + & - & + & + & - & - & - & + & + & + & + & + & + & + & + & - \\
\hline $\begin{array}{l}\text { Paenibacillus } \\
\text { hainanensis }\end{array}$ & $\begin{array}{l}\text { BKM } \\
32\end{array}$ & + & + & - & - & + & + & - & - & + & + & - & - & - & + & + & - & - & + & + & + & + & + \\
\hline
\end{tabular}

$(+)$ : tolerant (growth of bacterial cell); (-): non-tolerant (no growth) 


\begin{tabular}{|c|c|c|c|c|c|c|c|c|c|c|c|c|c|c|c|c|c|c|c|c|c|c|c|}
\hline \multirow[t]{2}{*}{ Strains } & & \multicolumn{4}{|c|}{$\mathrm{Zn}(\mathrm{mM})$} & \multicolumn{4}{|c|}{$\mathrm{Pb}(\mathrm{mM})$} & \multicolumn{5}{|c|}{$\mathrm{Cd}(\mathrm{mM})$} & \multicolumn{4}{|c|}{$\mathrm{Cu}(\mathrm{mM})$} & \multicolumn{5}{|c|}{$\begin{array}{l}\text { Mixture of } 4 \text { metals } \\
(\mathrm{mM})\end{array}$} \\
\hline & & 3 & 5 & 10 & 15 & 3 & 6 & 9 & 12 & 2 & 3 & 4 & 5 & 6 & 3 & 5 & 6 & 7 & 0.2 & 0.5 & 1 & 2 & 3 \\
\hline $\begin{array}{l}\text { Pseudomonas } \\
\text { koreensis }\end{array}$ & $\begin{array}{l}\text { BKM } \\
33\end{array}$ & + & + & - & - & + & + & - & - & + & + & - & - & - & + & + & + & + & + & + & + & + & - \\
\hline $\begin{array}{l}\text { Advenella } \\
\text { kashmerensis }\end{array}$ & $\begin{array}{l}\text { BKM } \\
19\end{array}$ & + & + & + & + & + & + & - & - & + & + & + & + & - & + & + & + & + & + & + & + & + & + \\
\hline $\begin{array}{l}\text { Bacillus } \\
\text { aryabhattai }\end{array}$ & $\begin{array}{l}\text { BKM } \\
34\end{array}$ & + & + & - & - & + & + & - & - & - & - & - & - & - & + & + & + & + & + & + & + & - & - \\
\hline $\begin{array}{l}\text { Pseudomonas } \\
\text { frederiksbergensis }\end{array}$ & $\begin{array}{l}\text { BKM } \\
18\end{array}$ & + & + & + & + & + & + & + & - & + & + & + & + & + & + & + & + & + & + & + & + & - & - \\
\hline
\end{tabular}

\subsection{Effect of salt and metallic stress on PGP activities}

The effect of salt and multi-metal stress on PGP activities of the selected rhizobacterial strains is presented in Table 3.All of the tested rhizobacteria were able to produce IAA under salt and heavy metal stress conditions. The indole phytohormones production in all tested rhizobacteria is significantly reduced by 0.65 to 3.5-fold under stressful conditions, except for BKM 19, BKM 20 and BKM 33 strains which does not show any change in their IAA production and BKM 28 which exhibited a significant increase in IAA biosynthesis, ranging up to 1.5-foldunder metallic pressure as compared to the control. The highest amount of IAA produced under non-stressed and stressed conditions was recorded for three strains, namely Mesorhizobium tamadayense BKM 04with $194.41 \mu \mathrm{g} \mathrm{mL}^{-1}$ and $153.07 \mu \mathrm{g} \mathrm{mL}^{-1}$ in control and metallic stress pressure respectively, followed by Streptomyces caelestis BKM $05 \mathrm{with}^{179.93 \mu \mathrm{g} \mathrm{mL}} \mathrm{m}^{-1}$ without stress and $121.25 \mu \mathrm{g} \mathrm{mL}^{-1}$ under metallic stress respectively, and Bacillus subtilis subsp. Inaquosorum BKM 06 with $119.73 \mu \mathrm{g} \mathrm{mL} \mathrm{m}^{-1}$ and $98.32 \mu \mathrm{g}$ $\mathrm{mL}^{-1}$ in control conditions and metallic stress treatment respectively. Phosphate solubilization ability of the studied rhizobacteria decreased by about 1.2 to 1.4- fold under salt stress, except for BKM 22 for which no significant change was observed. Enterobacter xiangfangensis BKM 30 appeared to maintain the highest phosphate solubilizing ability with $71.91 \mu \mathrm{g} \mathrm{P}_{2} \mathrm{O}_{2} \mathrm{~mL}^{-1}$ in control and $60.42 \mu \mathrm{g} \mathrm{P}_{2} \mathrm{O}_{2} \mathrm{~mL}^{-1}$ under osmotic stress, followed by Advenella kashmerensis BKM 20 with $53.89 \mu \mathrm{g} \mathrm{P}_{2} \mathrm{O}_{2} \mathrm{~mL}^{-1}$ in control and $49.94 \mu \mathrm{g} \mathrm{P}_{2} \mathrm{O}_{2} \mathrm{~mL}^{-1}$ under salt stress, and the lowest values were observed in Advenella kashmerensis BKM 19 and P.luteola BKM23. Moreover, the result suggested that metal stress contributes highly to the reduction in strains phosphate solubilization capacity in comparison to the salt stress. All other bacteria did not show any phosphate solubilizing ability under stress pressure neither on control conditions. Further, results suggested that the ammonia production was higher for all strains when cells were exposed to the multi-metal solution comparative to the unstressed conditions. However, the growth of BKM 06, BKM07, BKM 28 and BKM 19 with high concentration of NaCl leads to the loss of their capacity to produce ammonia as shown in the Table 3.Besides, fourteen rhizobacteria were found positive for siderophores production under control conditions. Whereas, salt stress induced a significant reduction in siderophores production compared to the control (e.g. the production of this compound by BKM 20and BKM 18 strains is completely inhibited in response to $\mathrm{NaCl}$ at $10 \%$ ). However, under metallic stress the siderophores production seems to be more produced for all the strains in comparison to the control conditions. 
Table 3

Plant growth promoting traits of osmotolerant-rhizobacteria under salt $\left(100 \mathrm{~g} \mathrm{~L}^{-1}\right)$ and multi-metals tress

\begin{tabular}{|c|c|c|c|c|c|c|c|c|c|c|c|c|}
\hline \multirow[b]{2}{*}{ Strains } & \multicolumn{3}{|c|}{$\mathrm{IAA}\left(\mu \mathrm{g} \mathrm{mL}^{-1}\right)$} & \multicolumn{3}{|c|}{$\mathrm{P}_{2} \mathrm{O}_{2}\left(\mu \mathrm{g} \mathrm{mL}^{-1}\right)$} & \multicolumn{3}{|c|}{ Ammonia } & \multicolumn{3}{|c|}{ Siderophores production } \\
\hline & Control & Salt stress & $\begin{array}{l}\text { Metallic } \\
\text { stress }^{*}\end{array}$ & Control & $\begin{array}{l}\text { Salt } \\
\text { stress }\end{array}$ & $\begin{array}{l}\text { Metallic } \\
\text { stress* }^{\star}\end{array}$ & Control & $\begin{array}{l}\text { Salt } \\
\text { stress }\end{array}$ & $\begin{array}{l}\text { Metallic } \\
\text { stress* }^{\star}\end{array}$ & Control & $\begin{array}{l}\text { Salt } \\
\text { stress }\end{array}$ & $\begin{array}{l}\text { Metallic } \\
\text { stress* }^{*}\end{array}$ \\
\hline $\begin{array}{l}\text { BKM } \\
04\end{array}$ & $\begin{array}{l}194.41 \pm \\
0.32^{\mathrm{a}, \mathrm{A}}\end{array}$ & $\begin{array}{l}121.36 \pm \\
0.82^{a, C}\end{array}$ & $\begin{array}{l}153.07 \pm \\
1.25^{\mathrm{a}, \mathrm{B}}\end{array}$ & - & - & & +++ & ++ & +++ & +++ & + & ++++ \\
\hline $\begin{array}{l}\text { BKM } \\
05\end{array}$ & $\begin{array}{l}179.93 \pm \\
0.16^{b, A}\end{array}$ & $\begin{array}{l}104.09 \pm \\
0.18^{\mathrm{c}, \mathrm{B}}\end{array}$ & $\begin{array}{l}121.25 \pm \\
0.06^{b, c}\end{array}$ & - & - & & ++ & ++ & +++ & ++++ & ++ & ++++ \\
\hline $\begin{array}{l}\text { BKM } \\
06\end{array}$ & $\begin{array}{l}119.73 \pm \\
0.09^{c, A}\end{array}$ & $\begin{array}{l}94.73 \pm \\
0.18^{\mathrm{d}, \mathrm{B}}\end{array}$ & $\begin{array}{l}98.32 \pm \\
1.09^{b c, c}\end{array}$ & - & - & & + & - & ++ & +++ & + & ++++ \\
\hline $\begin{array}{l}\text { BKM } \\
07\end{array}$ & $\begin{array}{l}31.58 \pm \\
0.03^{1, A}\end{array}$ & $\begin{array}{l}14.77 \pm \\
0.05^{\mathrm{k}, \mathrm{B}}\end{array}$ & $\begin{array}{l}5.11 \pm \\
0.11^{\mathrm{k}, \mathrm{C}}\end{array}$ & - & - & & ++ & - & +++ & + & + & +++ \\
\hline $\begin{array}{l}\text { BKM } \\
10\end{array}$ & $\begin{array}{l}92.73 \pm \\
0.18^{\mathrm{h}, \mathrm{A}}\end{array}$ & $\begin{array}{l}75.55 \pm \\
0.18^{\mathrm{e}, \mathrm{B}}\end{array}$ & $\begin{array}{l}7.89 \pm \\
0.20^{\mathrm{jk}, \mathrm{C}}\end{array}$ & - & - & & +++ & ++ & ++++ & +++ & + & ++++ \\
\hline $\begin{array}{l}\text { BKM } \\
14\end{array}$ & $\begin{array}{l}107.41 \pm \\
0.45^{f, A}\end{array}$ & $\begin{array}{l}78.45 \pm \\
0.18^{\mathrm{b}, \mathrm{B}}\end{array}$ & $\begin{array}{l}25.61 \pm \\
0.02^{\text {de,C }}\end{array}$ & - & - & & + & + & ++ & +++ & + & ++++ \\
\hline $\begin{array}{l}\text { BKM } \\
19\end{array}$ & $\begin{array}{l}35.18 \pm \\
0.32^{\mathrm{j}, \mathrm{A}}\end{array}$ & $\begin{array}{l}23.82 \pm \\
0.05^{h, B}\end{array}$ & $\begin{array}{l}30.23 \pm \\
0.18^{\mathrm{g}, \mathrm{A}}\end{array}$ & $\begin{array}{l}27.07 \pm \\
0.23^{d, A}\end{array}$ & $\begin{array}{l}22.42 \pm \\
0.86^{\mathrm{e}, \mathrm{B}}\end{array}$ & $\begin{array}{l}18.52 \pm \\
0.34^{c, C}\end{array}$ & + & - & ++ & +++ & ++ & +++ \\
\hline $\begin{array}{l}\text { BKM } \\
18\end{array}$ & $\begin{array}{l}48.64 \pm \\
0.23^{\mathrm{i}, \mathrm{A}}\end{array}$ & $\begin{array}{l}13.55 \pm \\
0.09^{1, C}\end{array}$ & $\begin{array}{l}20.73 \pm \\
0.68^{\text {cd, } B}\end{array}$ & - & - & & ++ & + & +++ & + & - & +++ \\
\hline $\begin{array}{l}\text { BKM } \\
20\end{array}$ & $\begin{array}{l}20.49 \pm \\
14.20^{\mathrm{m}, \mathrm{A}}\end{array}$ & $\begin{array}{l}9.39 \pm \\
0.02^{\mathrm{m}, \mathrm{B}}\end{array}$ & $\begin{array}{l}20.11 \pm \\
0.11^{\mathrm{g}, \mathrm{A}}\end{array}$ & $\begin{array}{l}53.89 \pm \\
0.12^{\mathrm{b}, \mathrm{A}}\end{array}$ & $\begin{array}{l}49.94 \pm \\
0.70^{\mathrm{b}, \mathrm{B}}\end{array}$ & $\begin{array}{l}30.33 \pm \\
0.06^{b, c}\end{array}$ & ++ & + & +++ & + & - & +++ \\
\hline $\begin{array}{l}\text { BKM } \\
21\end{array}$ & $\begin{array}{l}33.27 \pm \\
0.05^{\mathrm{k}, \mathrm{A}}\end{array}$ & $\begin{array}{l}25.45 \pm \\
0.32^{g, B}\end{array}$ & $\begin{array}{l}15.34 \pm \\
1.84^{h, C}\end{array}$ & - & - & & +++ & + & ++ & + & + & +++ \\
\hline $\begin{array}{l}\text { BKM } \\
22\end{array}$ & $\begin{array}{l}30.77 \pm \\
0.41^{1, A}\end{array}$ & $\begin{array}{l}15.98 \pm \\
0.11^{\mathrm{j}, \mathrm{B}}\end{array}$ & $\begin{array}{l}15.75 \pm \\
2.52^{\mathrm{h}, \mathrm{C}}\end{array}$ & $\begin{array}{l}30.26 \pm \\
0.03^{c, A}\end{array}$ & $\begin{array}{l}30.00 \pm \\
0.60^{c, A}\end{array}$ & $\begin{array}{l}29.65 \pm \\
0.05^{\mathrm{b}, \mathrm{A}}\end{array}$ & +++ & + & +++ & - & - & - \\
\hline $\begin{array}{l}\text { BKM } \\
23\end{array}$ & $\begin{array}{l}30.25 \pm \\
0.34^{1, A}\end{array}$ & $\begin{array}{l}18.25 \pm \\
0.30^{i, C}\end{array}$ & $\begin{array}{l}23.80 \pm \\
1.56^{\mathrm{fg}, \mathrm{B}}\end{array}$ & $\begin{array}{l}18.84 \pm \\
0.35^{\mathrm{e}, \mathrm{A}}\end{array}$ & $\begin{array}{l}13.58 \pm \\
0.78^{d, B}\end{array}$ & $\begin{array}{l}10.45 \pm \\
0.25^{b, c}\end{array}$ & ++ & + & +++ & - & - & - \\
\hline $\begin{array}{l}\text { BKM } \\
26\end{array}$ & $\begin{array}{l}68.23 \pm \\
0.05^{\mathrm{g}, \mathrm{A}}\end{array}$ & $\begin{array}{l}13.36 \pm \\
0.23^{1, C}\end{array}$ & $\begin{array}{l}30.91 \pm \\
0.22^{\mathrm{d}, \mathrm{B}}\end{array}$ & - & - & & ++ & + & +++ & ++ & + & +++ \\
\hline $\begin{array}{l}\text { BKM } \\
27\end{array}$ & $\begin{array}{l}86.59 \pm \\
0.14^{\mathrm{e}, \mathrm{B}}\end{array}$ & $\begin{array}{l}9.86 \pm \\
0.73^{m, c}\end{array}$ & $\begin{array}{l}129.89 \pm \\
1.02^{\mathrm{b}, \mathrm{A}}\end{array}$ & - & - & & ++ & + & ++ & +++ & ++ & +++ \\
\hline $\begin{array}{l}\text { BKM } \\
28\end{array}$ & $\begin{array}{l}12.30 \pm \\
0.16^{n, B}\end{array}$ & $\begin{array}{l}9.39 \pm \\
0.25^{\mathrm{m}, \mathrm{c}}\end{array}$ & $\begin{array}{l}25.52 \pm \\
0.25^{\text {ef,A }}\end{array}$ & - & - & & + & - & +++ & ++ & + & ++ \\
\hline $\begin{array}{l}\text { BKM } \\
30\end{array}$ & $\begin{array}{l}110.05 \pm \\
0.14^{d, A}\end{array}$ & $\begin{array}{l}33.50 \pm \\
0.05^{f, C}\end{array}$ & $\begin{array}{l}52.16 \pm \\
0.34^{\mathrm{c}, \mathrm{B}}\end{array}$ & $\begin{array}{l}71.91 \pm \\
0.80^{\mathrm{a}, \mathrm{A}}\end{array}$ & $\begin{array}{l}60.42 \pm \\
0.07^{a, B}\end{array}$ & $\begin{array}{l}40.23 \pm \\
0.34^{a, C}\end{array}$ & ++ & ++ & ++++ & - & - & - \\
\hline $\begin{array}{l}\text { BKM } \\
33\end{array}$ & $\begin{array}{l}22.18 \pm \\
0.09^{m, B}\end{array}$ & $\begin{array}{l}25.84 \pm \\
0.02^{\mathrm{g}, \mathrm{A}}\end{array}$ & $\begin{array}{l}22.70 \pm \\
0.07^{f g, B}\end{array}$ & - & - & & +++ & + & +++ & + & + & +++ \\
\hline $\begin{array}{l}\text { IAA and } \\
\text { significa } \\
\text { significa } \\
\text { and met } \\
(++), \text { mo }\end{array}$ & $\begin{array}{l}\mathrm{O}_{2} \text { are exp } \\
\text { y differen } \\
\text { difference } \\
\text { c stress) } \\
\text { ate; }(+++)\end{array}$ & $\begin{array}{l}\text { ed as mean } \\
\text { st-hoc Stud } \\
\text { nong strain } \\
\text { very strains } \\
\text { ong; (++++), }\end{array}$ & $\begin{array}{l}\text { SE }(n=3 \\
\text { t Newmar } \\
\text { or the san } \\
\text { cording } t \\
\text { ry strong }\end{array}$ & $\begin{array}{l}\text { Letter co } \\
\text { uls test ( } \\
\text { eatment } \\
\text { st-hoc St }\end{array}$ & $\begin{array}{l}\text { are shov } \\
.05) \text {.Diff } \\
\text { ital letter } \\
\text { nt Newm } \\
\mathrm{Cu}, \mathrm{Pb}, \mathrm{C}\end{array}$ & $\begin{array}{l}\text { r signific } \\
\text { t letters re } \\
\text { w signific } \\
\text { euls test } \\
\text { d Zn at } 0\end{array}$ & $\begin{array}{l}\text { ANOVA, } \\
\text { to signifi } \\
\text { differen } \\
0.05) .(-)\end{array}$ & $\begin{array}{l}\text { ain value } \\
\text { ant differ } \\
\text { s betwee } \\
\text { ot detec } \\
\text { metal }\end{array}$ & $\begin{array}{l}\text { showing } \\
\text { nces }(p< \\
\text { i differen } \\
\text { able/no p }\end{array}$ & $\begin{array}{l}\text { same let } \\
\text { ); lowerc } \\
\text { atments ( } \\
\text { uction; (+) }\end{array}$ & $\begin{array}{l}\text { code a } \\
\text { se letter } \\
\text { ontrol, s } \\
\text { positive }\end{array}$ & $\begin{array}{l}\text { not } \\
\text { how } \\
\text { t stress } \\
\text { veak; }\end{array}$ \\
\hline
\end{tabular}

\subsection{Bacterial response to salinity and metallic stress}

The response of the 17 selected rhizobacterial strains to multi-metal and high level of salt stress was studied by evaluating the physiological and biochemical status in terms of proline, soluble sugars, proteins and free amino acids contents as well as their ability to produce exopolysaccharides (Tables 4 and 5) under metallic and salt stress. The results showed that all bacterial strains produce high content of EPS under osmotic stress than control. Indeed, the exposure of rhizobacteria to multi-metal or salt stress resulted in a significant increase of EPS production by an average of 4 and 2 times, respectively, if compared to salt stressed and unstressed ones. The highest amount of EPS was produced by BKM 04, BKM 07, BKM10, BKM26 and BKM 33up of $195 \mu \mathrm{g} \mathrm{mL}^{-1}$ under heavy metal stress (Table 4). 
Table 4

Exopolysaccharides (EPS) and proteins production of osmo-tolerantrhizobacteria under mixture of heavy metal $(0.5 \mathrm{mM}$ of $\mathrm{Cu}, \mathrm{Pb}, \mathrm{Zn}$ and $\mathrm{Cd})$ and salt stress $\left(100 \mathrm{~g} \mathrm{~L}^{-1}\right)$

\begin{tabular}{|c|c|c|c|c|c|c|}
\hline \multirow[t]{2}{*}{ Strains } & \multicolumn{3}{|c|}{ EPS concentration ( $\left.\mu \mathrm{g} \mathrm{mL}^{-1}\right)$} & \multicolumn{3}{|c|}{ Proteins $\left(\mu \mathrm{g} \mathrm{mL}^{-1}\right)$} \\
\hline & Control & Salt stress & Metallic stress & Control & Salt stress & Metallic stress \\
\hline BKM 04 & $41.38 \pm 0.40^{\mathrm{l}, \mathrm{C}}$ & $100.00 \pm 0.00^{\mathrm{m}, \mathrm{B}}$ & $195.08 \pm 0.03^{b, A}$ & $17.66 \pm 0.18^{\mathrm{i}, \mathrm{B}}$ & $08.42 \pm 0.04^{\mathrm{g}, \mathrm{C}}$ & $201.15 \pm 1.50^{\mathrm{c}, \mathrm{A}}$ \\
\hline BKM 05 & $46.17 \pm 0.10^{\mathrm{e}, \mathrm{C}}$ & $98.14 \pm 0.03^{g, B}$ & $145.16 \pm 0.02^{\mathrm{fg}, \mathrm{A}}$ & $27.06 \pm 0.02^{f, B}$ & $10.31 \pm 0.07^{\mathrm{e}, \mathrm{C}}$ & $99.15 \pm 3.40^{\mathrm{h}, \mathrm{A}}$ \\
\hline BKM 06 & $39.59 \pm 0.07^{m, c}$ & $96.45 \pm 0.00^{\mathrm{h}, \mathrm{B}}$ & $143.83 \pm 0.04^{\mathrm{ghi}, \mathrm{C}}$ & $14.42 \pm 0.10^{\mathrm{i}, \mathrm{B}}$ & $08.62 \pm 0.04^{\mathrm{g}, \mathrm{C}}$ & $114.00 \pm 1.05^{\mathrm{gh}, \mathrm{A}}$ \\
\hline BKM 07 & $44.81 \pm 0.08^{\mathrm{i}, \mathrm{C}}$ & $98.86 \pm 0.49^{d, B}$ & $196.49 \pm 0.06^{\mathrm{aA}}$ & $14.95 \pm 0.06^{\mathrm{k}, \mathrm{B}}$ & $07.35 \pm 0.06^{\mathrm{h}, \mathrm{C}}$ & $57.50 \pm 0.51^{\mathrm{jk}, \mathrm{A}}$ \\
\hline BKM 10 & $43.02 \pm 0.02^{\mathrm{k}, \mathrm{C}}$ & $100.00 \pm 0.01^{n, B}$ & $191.76 \pm 0.07^{\mathrm{c}, \mathrm{A}}$ & $12.24 \pm 0.08^{\mathrm{e}, \mathrm{B}}$ & $10.92 \pm 0.05^{\mathrm{e}, \mathrm{B}}$ & $151.10 \pm 1.30^{\mathrm{e}, \mathrm{A}}$ \\
\hline BKM 14 & $43.51 \pm 0.03^{\mathrm{k}, \mathrm{C}}$ & $99.22 \pm 0.03^{\mathrm{b}, \mathrm{B}}$ & $194.29 \pm 0.52^{b, A}$ & $30.38 \pm 0.22^{\mathrm{c}, \mathrm{B}}$ & $12.73 \pm 0.03^{\mathrm{d}, \mathrm{C}}$ & $133.00 \pm 1.20^{\mathrm{ef}, \mathrm{A}}$ \\
\hline BKM 19 & $45.42 \pm 0.01^{g, c}$ & $95.73 \pm 0.06^{\mathrm{j}, \mathrm{B}}$ & $180.68 \pm 0.57^{d, A}$ & $18.69 \pm 0.08^{h, B}$ & $09.30 \pm 0.06^{f, C}$ & $77.20 \pm 0.41^{\mathrm{i}, \mathrm{A}}$ \\
\hline BKM 18 & $47.22 \pm 0.03^{\mathrm{c}, \mathrm{C}}$ & $92.85 \pm 0.00^{\mathrm{e}, \mathrm{B}}$ & $144.69 \pm 0.05^{\mathrm{fgh}, \mathrm{A}}$ & $25.40 \pm 0.12^{h, B}$ & $09.35 \pm 0.04^{f, C}$ & $262.20 \pm 0.31^{\mathrm{a}, \mathrm{A}}$ \\
\hline BKM 20 & $49.35 \pm 0.10^{\mathrm{a}, \mathrm{c}}$ & $98.71 \pm 0.06^{\mathrm{c}, \mathrm{B}}$ & $175.12 \pm 0.16^{\mathrm{e}, \mathrm{A}}$ & $24.53 \pm 0.06^{\mathrm{i}, \mathrm{B}}$ & $14.53 \pm 0.74^{\mathrm{b}, \mathrm{c}}$ & $77.70 \pm 3.32^{\mathrm{i}, \mathrm{A}}$ \\
\hline BKM 21 & $45.88 \pm 0.01^{f, C}$ & $96.23 \pm 0.01^{\mathrm{h}, \mathrm{B}}$ & $144.47 \pm 0.25 f^{\text {gh,A }}$ & $23.38 \pm 0.02^{g, B}$ & $09.74 \pm 0.05^{f, C}$ & $220.95 \pm 1.51^{b, A}$ \\
\hline BKM 22 & $45.16 \pm 0.02^{h, c}$ & $96.28 \pm 0.02^{h, B}$ & $146.19 \pm 0.03^{f, A}$ & $14.40 \pm 0.16^{\mathrm{l}, \mathrm{B}}$ & $05.05 \pm 0.06^{h, c}$ & $175.50 \pm 0.33^{d, A}$ \\
\hline BKM 23 & $44.37 \pm 0.02^{\mathrm{j}, \mathrm{C}}$ & $95.01 \pm 0.48^{\mathrm{i}, \mathrm{B}}$ & $143.73 \pm 0.09 \mathrm{ghi}, \mathrm{A}$ & $12.76 \pm 0.12^{\mathrm{j}, \mathrm{B}}$ & $08.05 \pm 0.05^{g, C}$ & $193.00 \pm 2.44^{\mathrm{cd}, A}$ \\
\hline BKM 26 & $45.06 \pm 0.03^{h i, c}$ & $96.45 \pm 0.19^{h, B}$ & $191.83 \pm 0.05^{\mathrm{C}, \mathrm{A}}$ & $14.38 \pm 0.14^{\mathrm{k}, \mathrm{B}}$ & $07.41 \pm 0.04^{\mathrm{h}, \mathrm{C}}$ & $57.50 \pm 1.25^{\mathrm{jk}, \mathrm{A}}$ \\
\hline BKM 27 & $46.49 \pm 0.03^{\mathrm{d}, \mathrm{C}}$ & $97.62 \pm 0.38^{f, B}$ & $143.05 \pm 1.59^{h i, A}$ & $20.66 \pm 0.42^{b, B}$ & $13.76 \pm 0.02^{\mathrm{c}, \mathrm{C}}$ & $117.90 \pm 2.55^{\mathrm{fg}, \mathrm{A}}$ \\
\hline BKM 28 & $47.97 \pm 0.34^{\mathrm{b}, \mathrm{c}}$ & $100.00 \pm 0.02^{\mathrm{a}, \mathrm{B}}$ & $193.39 \pm 0.30^{\mathrm{bc}, \mathrm{A}}$ & $18.23 \pm 0.14^{\mathrm{d}, \mathrm{B}}$ & $11.27 \pm 0.03^{\mathrm{e}, \mathrm{C}}$ & $46.60 \pm 2.43^{f, C}$ \\
\hline BKM 30 & $44.85 \pm 0.09^{\mathrm{i}, \mathrm{C}}$ & $93.86 \pm 0.01^{\mathrm{k}, \mathrm{B}}$ & $142.83 \pm 0.31^{\mathrm{i}, \mathrm{A}}$ & $24.20 \pm 0.16^{\mathrm{a}, \mathrm{B}}$ & $15.16 \pm 0.08^{\mathrm{a}, \mathrm{c}}$ & $261.00 \pm 1.53^{\mathrm{a}, \mathrm{A}}$ \\
\hline BKM 33 & $44.82 \pm 0.01^{1, \mathrm{C}}$ & $92.34 \pm 0.01^{1, \mathrm{~B}}$ & $196.71 \pm 0.03^{\mathrm{a}, \mathrm{A}}$ & $12.30 \pm 0.06^{\mathrm{k}, \mathrm{B}}$ & $07.37 \pm 0.07^{\mathrm{h}, \mathrm{C}}$ & $190.80 \pm 0.52^{\mathrm{cd}, \mathrm{A}}$ \\
\hline
\end{tabular}


Table 5

Contents of total soluble sugars, amino-acids and proline in osmo-tolerant rhizobacteria cells grown under salt (100g L $\left.\mathrm{L}^{-1} \mathrm{NaCl}\right)$ and multi-metallic stress conditions ( $\mathrm{Cu}, \mathrm{Pb}, \mathrm{Cd}$ and $\mathrm{Zn}$ at $0.5 \mathrm{mM}$ for each metal)

\begin{tabular}{|c|c|c|c|c|c|c|c|c|c|}
\hline \multirow[b]{2}{*}{$\begin{array}{l}\text { Bacterial } \\
\text { strains }\end{array}$} & \multicolumn{3}{|c|}{ Soluble sugars ( $\mu \mathrm{g} \mathrm{mL}^{-1}$ ) } & \multicolumn{3}{|c|}{ Amino-acids $\left(\mu \mathrm{mol} \mathrm{mL}{ }^{-1}\right)$} & \multicolumn{3}{|c|}{ Proline ( $\left.\mu \mathrm{g} \mathrm{mL}^{-1}\right)$} \\
\hline & Control & Salt stress & $\begin{array}{l}\text { Metallic } \\
\text { stress }\end{array}$ & Control & Salt stress & $\begin{array}{l}\text { Metallic } \\
\text { stress }\end{array}$ & Control & Salt stress & Metallic stress \\
\hline BKM 04 & $\begin{array}{l}27.619 \pm \\
0.436^{c, C}\end{array}$ & $\begin{array}{l}75.810 \pm \\
0.330^{\mathrm{b}, \mathrm{B}}\end{array}$ & $\begin{array}{l}106.43 \pm \\
0.42^{\mathrm{b}, \mathrm{A}}\end{array}$ & $\begin{array}{l}23.02 \pm \\
0.19^{h, C}\end{array}$ & $\begin{array}{l}65.28 \pm \\
0.21^{d, B}\end{array}$ & $\begin{array}{l}570.3 \pm \\
2.4^{\mathrm{bc}, \mathrm{A}}\end{array}$ & $\begin{array}{l}112.10 \pm \\
0.18^{g, B}\end{array}$ & $\begin{array}{l}349.85 \pm \\
0.27^{d, A}\end{array}$ & $\begin{array}{l}130.54 \pm \\
1.23^{f g, C}\end{array}$ \\
\hline BKM 05 & $\begin{array}{l}21.524 \pm \\
0.165^{\mathrm{e}, \mathrm{C}}\end{array}$ & $\begin{array}{l}75.714 \pm \\
0.571^{\mathrm{c}, \mathrm{A}}\end{array}$ & $\begin{array}{l}71.43 \pm \\
1.14^{\mathrm{def}, \mathrm{B}}\end{array}$ & $\begin{array}{l}22.98 \pm \\
0.16^{\mathrm{i}, \mathrm{A}}\end{array}$ & $\begin{array}{l}51.23 \pm \\
0.12^{\mathrm{h}, \mathrm{A}}\end{array}$ & $\begin{array}{l}331.5 \pm \\
0.9^{e, A}\end{array}$ & $\begin{array}{l}142.36 \pm \\
0.18^{\mathrm{e}, \mathrm{B}}\end{array}$ & $\begin{array}{l}343.54 \pm \\
0.53^{\mathrm{e}, \mathrm{A}}\end{array}$ & $\begin{array}{l}149.62 \pm \\
1.69^{\text {cdef, }}\end{array}$ \\
\hline BKM 06 & $\begin{array}{l}15.905 \pm \\
0.436^{f, C}\end{array}$ & $\begin{array}{l}53.810 \pm \\
0.165^{\mathrm{d}, \mathrm{A}}\end{array}$ & $\begin{array}{l}31.43 \pm \\
0.28^{i, B}\end{array}$ & $\begin{array}{l}34.36 \pm \\
0.18^{c, C}\end{array}$ & $\begin{array}{l}43.73 \pm \\
0.20^{\mathrm{j}, \mathrm{B}}\end{array}$ & $\begin{array}{l}552.3 \pm \\
3.6^{\mathrm{c}, \mathrm{A}}\end{array}$ & $\begin{array}{l}136.82 \pm \\
0.33^{f, B}\end{array}$ & $\begin{array}{l}215.08 \pm \\
0.92^{\mathrm{g}, \mathrm{A}}\end{array}$ & $\begin{array}{l}152.62 \pm \\
1.02^{\text {cde, } C}\end{array}$ \\
\hline BKM 07 & $\begin{array}{l}13.714 \pm \\
0.286^{\text {h,C }}\end{array}$ & $\begin{array}{l}45.619 \pm \\
0.595^{f, B}\end{array}$ & $\begin{array}{l}66.71 \pm \\
1.05^{\text {def,A }}\end{array}$ & $\begin{array}{l}25.94 \pm \\
0.03^{\mathrm{g}, \mathrm{C}}\end{array}$ & $\begin{array}{l}59.73 \pm \\
0.44^{\mathrm{e}, \mathrm{B}}\end{array}$ & $\begin{array}{l}74.8 \pm \\
0.2^{\mathrm{h}, \mathrm{A}}\end{array}$ & $\begin{array}{l}89.23 \pm \\
0.06^{1, B}\end{array}$ & $\begin{array}{l}237.64 \pm \\
0.71^{a, A}\end{array}$ & $\begin{array}{l}179.23 \pm \\
0.15^{\mathrm{abc}, \mathrm{c}}\end{array}$ \\
\hline BKM 10 & $\begin{array}{l}35.905 \pm \\
0.873^{a, C}\end{array}$ & $\begin{array}{l}73.524 \pm \\
0.330^{\mathrm{a}, \mathrm{B}}\end{array}$ & $\begin{array}{l}79.29 \pm \\
1.57^{\mathrm{cd}, \mathrm{A}}\end{array}$ & $\begin{array}{l}12.54 \pm \\
0.30^{1, C}\end{array}$ & $\begin{array}{l}33.39 \pm \\
0.54^{\mathrm{k}, \mathrm{B}}\end{array}$ & $\begin{array}{l}146.1 \pm \\
1.5^{\mathrm{g}, \mathrm{A}}\end{array}$ & $\begin{array}{l}84.92 \pm \\
0.62^{m, B}\end{array}$ & $\begin{array}{l}146.62 \pm \\
0.53^{n, A}\end{array}$ & $\begin{array}{l}189.00 \pm \\
0.92^{\mathrm{ab}, \mathrm{B}}\end{array}$ \\
\hline BKM 14 & $\begin{array}{l}30.190 \pm \\
0.165^{\mathrm{b}, \mathrm{C}}\end{array}$ & $\begin{array}{l}72.762 \pm \\
0.165^{\mathrm{a}, \mathrm{B}}\end{array}$ & $\begin{array}{l}156.29 \pm \\
1.28^{\mathrm{a}, \mathrm{A}}\end{array}$ & $\begin{array}{l}40.16 \pm \\
0.15^{b, B}\end{array}$ & $\begin{array}{l}74.88 \pm \\
0.32^{a, A}\end{array}$ & $\begin{array}{l}23.7 \pm \\
1.3^{i, C}\end{array}$ & $\begin{array}{l}155.28 \pm \\
0.28^{d, B}\end{array}$ & $\begin{array}{l}212.77 \pm \\
0.92^{\mathrm{h}, \mathrm{A}}\end{array}$ & $\begin{array}{l}162.46 \pm \\
0.61^{b c d, C}\end{array}$ \\
\hline BKM 19 & $\begin{array}{l}36.762 \pm \\
0.825^{a, B}\end{array}$ & $\begin{array}{l}64.190 \pm \\
0.436^{\mathrm{b}, \mathrm{A}}\end{array}$ & $\begin{array}{l}65.14 \pm \\
1.14^{\text {def,A }}\end{array}$ & $\begin{array}{l}39.88 \pm \\
0.15^{b, c}\end{array}$ & $\begin{array}{l}44.56 \pm \\
0.28^{\mathrm{i}, \mathrm{B}}\end{array}$ & $\begin{array}{l}598.7 \pm \\
1.3^{\mathrm{a}, \mathrm{A}}\end{array}$ & $\begin{array}{l}107.28 \pm \\
0.04^{h, B}\end{array}$ & $\begin{array}{l}173.08 \pm \\
0.46^{\mathrm{k}, \mathrm{A}}\end{array}$ & $\begin{array}{l}221.00 \pm \\
0.53^{\mathrm{g}, \mathrm{C}}\end{array}$ \\
\hline BKM 18 & $\begin{array}{l}26.667 \pm \\
0.825^{c, C}\end{array}$ & $\begin{array}{l}44.00 \pm \\
0.040^{\mathrm{g}, \mathrm{B}}\end{array}$ & $\begin{array}{l}71.00 \pm \\
1.06^{\mathrm{efg}, \mathrm{A}}\end{array}$ & $\begin{array}{l}21.10 \pm \\
0.44^{\mathrm{i}, \mathrm{C}}\end{array}$ & $\begin{array}{l}50.96 \pm \\
0.14^{\mathrm{h}, \mathrm{A}}\end{array}$ & $\begin{array}{l}438.9 \pm \\
7.5^{d, B}\end{array}$ & $\begin{array}{l}77.74 \pm \\
0.04^{\mathrm{n}, \mathrm{C}}\end{array}$ & $\begin{array}{l}168.62 \pm \\
0.70^{\mathrm{l}, \mathrm{A}}\end{array}$ & $\begin{array}{l}101.46 \pm \\
1.69^{a, B}\end{array}$ \\
\hline BKM 20 & $\begin{array}{l}24.00 \pm \\
0.286^{d, C}\end{array}$ & $\begin{array}{l}53.524 \pm \\
0.825^{\mathrm{d}, \mathrm{B}}\end{array}$ & $\begin{array}{l}87.57 \pm \\
2.41^{b c, A}\end{array}$ & $\begin{array}{l}26.86 \pm \\
0.15^{\mathrm{g}, \mathrm{C}}\end{array}$ & $\begin{array}{l}59.07 \pm \\
0.12^{f, B}\end{array}$ & $\begin{array}{l}138.6 \pm \\
1.6^{\mathrm{g}, \mathrm{A}}\end{array}$ & $\begin{array}{l}88.62 \pm \\
0.07^{1, B}\end{array}$ & $\begin{array}{l}144.77 \pm \\
0.27^{\circ, A}\end{array}$ & $\begin{array}{l}134.62 \pm \\
0.76^{\text {efg,C }}\end{array}$ \\
\hline BKM 21 & $\begin{array}{l}27.714 \pm \\
0.495^{\mathrm{c}, C}\end{array}$ & $\begin{array}{l}43.619 \pm \\
0.595^{\mathrm{g}, \mathrm{B}}\end{array}$ & $\begin{array}{l}46.00 \pm \\
0.57^{\mathrm{ghi}, \mathrm{A}}\end{array}$ & $\begin{array}{l}27.00 \pm \\
0.16^{g, C}\end{array}$ & $\begin{array}{l}44.29 \pm \\
0.05^{\mathrm{i}, \mathrm{B}}\end{array}$ & $\begin{array}{l}584.7 \pm \\
1.5^{a b, A}\end{array}$ & $\begin{array}{l}23.53 \pm \\
0.08^{c, C}\end{array}$ & $\begin{array}{l}162.26 \pm \\
0.53^{f, A}\end{array}$ & $\begin{array}{l}169.85 \pm \\
1.15^{\text {bcd,B }}\end{array}$ \\
\hline BKM 22 & $\begin{array}{l}12.667 \pm \\
0.873^{i, C}\end{array}$ & $\begin{array}{l}45.905 \pm \\
0.825^{f, B}\end{array}$ & $\begin{array}{l}73.86 \pm \\
2.42^{\text {de,A }}\end{array}$ & $\begin{array}{l}32.56 \pm \\
0.12^{d, C}\end{array}$ & $\begin{array}{l}72.51 \pm \\
0.58^{\mathrm{b}, \mathrm{B}}\end{array}$ & $\begin{array}{l}455.7 \pm \\
1.5^{\mathrm{d}, \mathrm{A}}\end{array}$ & $\begin{array}{l}198.56 \pm \\
0.28^{a, B}\end{array}$ & $\begin{array}{l}285.85 \pm \\
0.31^{b, A}\end{array}$ & $\begin{array}{l}156.92 \pm \\
1.05^{\text {bcd,C }}\end{array}$ \\
\hline BKM 23 & $\begin{array}{l}24.00 \pm \\
0.286^{d, C}\end{array}$ & $\begin{array}{l}53.524 \pm \\
0.825^{\mathrm{d}, A}\end{array}$ & $\begin{array}{l}37.00 \pm \\
0.14^{\text {hi,B }}\end{array}$ & $\begin{array}{l}13.48 \pm \\
0.39^{k, A}\end{array}$ & $\begin{array}{l}51.07 \pm \\
0.64^{\mathrm{h}, \mathrm{B}}\end{array}$ & $\begin{array}{l}331.8 \pm \\
0.9^{\mathrm{e}, \mathrm{A}}\end{array}$ & $\begin{array}{l}101.33 \pm \\
0.04^{\mathrm{j}, \mathrm{B}}\end{array}$ & $\begin{array}{l}184.23 \pm \\
0.27^{\mathrm{j}, \mathrm{A}}\end{array}$ & $\begin{array}{l}132.69 \pm \\
0.30^{\text {efg }, C}\end{array}$ \\
\hline BKM 26 & $\begin{array}{l}35.143 \pm \\
0.286^{a, C}\end{array}$ & $\begin{array}{l}68.762 \pm \\
0.165^{\mathrm{e}, \mathrm{A}}\end{array}$ & $\begin{array}{l}53.86 \pm \\
0.71^{\text {def, } B}\end{array}$ & $\begin{array}{l}14.58 \pm \\
0.12^{\mathrm{j}, \mathrm{A}}\end{array}$ & $\begin{array}{l}52.35 \pm \\
0.08^{g, B}\end{array}$ & $\begin{array}{l}99.4 \pm \\
2.4^{\mathrm{g}, \mathrm{A}}\end{array}$ & $\begin{array}{l}101.95 \pm \\
0.10^{\mathrm{i}, \mathrm{B}}\end{array}$ & $\begin{array}{l}199.23 \pm \\
0.71^{\mathrm{i}, \mathrm{A}}\end{array}$ & $\begin{array}{l}124.77 \pm \\
0.15^{\mathrm{fg}, \mathrm{C}}\end{array}$ \\
\hline BKM 27 & $\begin{array}{l}29.333 \pm \\
0.165^{b, c}\end{array}$ & $\begin{array}{l}45.714 \pm \\
0.756^{\mathrm{b}, \mathrm{B}}\end{array}$ & $\begin{array}{l}54.29 \pm \\
0.57^{f g h, A}\end{array}$ & $\begin{array}{l}47.62 \pm \\
0.18^{a, c}\end{array}$ & $\begin{array}{l}55.09 \pm \\
0.05^{\mathrm{g}, \mathrm{B}}\end{array}$ & $\begin{array}{l}572.1 \pm \\
4.5^{\mathrm{bc}, \mathrm{A}}\end{array}$ & $\begin{array}{l}95.18 \pm \\
0.09^{k, B}\end{array}$ & $\begin{array}{l}160.46 \pm \\
0.27^{\mathrm{m}, \mathrm{A}}\end{array}$ & $\begin{array}{l}126.15 \pm \\
0.61^{f g, C}\end{array}$ \\
\hline BKM 28 & $\begin{array}{l}26.667 \pm \\
0.825^{c, C}\end{array}$ & $\begin{array}{l}44.00 \pm \\
0.495^{\mathrm{g}, \mathrm{B}}\end{array}$ & $\begin{array}{l}148.29 \pm \\
0.82^{\mathrm{a}, \mathrm{A}}\end{array}$ & $\begin{array}{l}14.66 \pm \\
0.25^{\mathrm{j}, C}\end{array}$ & $\begin{array}{l}44.56 \pm \\
0.28^{\mathrm{i}, \mathrm{B}}\end{array}$ & $\begin{array}{l}155.6 \pm \\
2^{f g, A}\end{array}$ & $\begin{array}{l}76.72 \pm \\
0.09^{n, B}\end{array}$ & $\begin{array}{l}123.89 \pm \\
0.77^{\mathrm{p}, \mathrm{A}}\end{array}$ & $\begin{array}{l}123.69 \pm \\
0.15^{f g, C}\end{array}$ \\
\hline BKM 30 & $\begin{array}{l}30.190 \pm \\
0.165^{\mathrm{b}, \mathrm{C}}\end{array}$ & $\begin{array}{l}53.905 \pm \\
0.165^{\mathrm{d}, \mathrm{A}}\end{array}$ & $\begin{array}{l}41.29 \pm \\
1.06^{h i, B}\end{array}$ & $\begin{array}{l}29.12 \pm \\
0.19^{e, C}\end{array}$ & $\begin{array}{l}51.57 \pm \\
0.09^{h, B}\end{array}$ & $\begin{array}{l}175.8 \pm \\
2.7^{f, A}\end{array}$ & $\begin{array}{l}75.69 \pm \\
0.60^{n, B}\end{array}$ & $\begin{array}{l}159.84 \pm \\
0.07^{\mathrm{m}, \mathrm{A}}\end{array}$ & $\begin{array}{l}135.38 \pm \\
1.02^{\mathrm{efg}, \mathrm{C}}\end{array}$ \\
\hline BKM 33 & $\begin{array}{l}13.714 \pm \\
0.286^{g, C}\end{array}$ & $\begin{array}{l}35.714 \pm \\
0.286^{h, B}\end{array}$ & $\begin{array}{l}122.14 \pm \\
1.28^{b, A}\end{array}$ & $\begin{array}{l}27.28 \pm \\
0.09^{f, C}\end{array}$ & $\begin{array}{l}66.10 \pm \\
0.18^{c, B}\end{array}$ & $\begin{array}{l}84.5 \pm \\
1.3^{h, A}\end{array}$ & $\begin{array}{l}168.21 \pm \\
0.50^{\mathrm{b}, \mathrm{B}}\end{array}$ & $\begin{array}{l}262.62 \pm \\
0.27^{c, A}\end{array}$ & $\begin{array}{l}149.92 \pm \\
0.84^{\text {cdef,C }}\end{array}$ \\
\hline
\end{tabular}

Soluble sugar contents were significantly higher when cells were exposed to metallic stress compared to salt stress and non-stressed conditions (Table 5), with the highest values were recorded with five strains belonging to M. tamadayense, C. rlividus, P. frederiks bergensis and P. koreensis (BKM 04 , BKM 28, BKM 14and BKM 33). Moreover, results revealed that the free amino acids levels of all bacteria increased by 2.2 times under salt stress and more than 13 time under metallic stress in comparison to the control. The highest amounts of free amino acids recorded was $570.3 \mu \mathrm{mol} \mathrm{mL}-1,552.3 \mu \mathrm{mol} \mathrm{mL}{ }^{-1}, 598.7$ $\mu \mathrm{mol} \mathrm{mL}-1$ and $584.7 \mu \mathrm{mol} \mathrm{mL} \mathrm{m}^{-1}$ under metallic stress for BKM 04, BKM 06, BKM 19 and BKM 21 strains, respectively. Similarly, proline concentration also increased significantly in all rhizobacteria under salt and heavy metal stress, with the highest production was recorded for BKM 04 , BKM 05 and BKM 33 under salt stress (Table 5). However, a decrease in cell proteins contents was observed in all tested bacteria grown under salt stressed conditions compared to the control. While, the amount of proteins increased by more than 11 times when cells were exposed to heavy metal stress (Table 4). 


\subsection{Effect of PGPR inoculation on seedling shoot and root growth under metallic and salt stress}

The effect of inoculation with consortium of four PGPR (Mesorhizobium tamadayense BKM 04, Enterobacter xiangfangensis BKM 30 , Pseudomonas azotifigens BKM 07 and Streptomyces Caelestis BKM 05) on root and shoot elongation of wild rue and lettuce seedlings subjected to metal and salt stress is presented in Figs. 1 and 2. In general, a significant decrease in roots and shoots growth of the two species was observed with increasing concentrations of metal or salt concentrations. In addition, bacterial inoculated plants showed significantly higher growth in terms of root and shoot length, as compared to uninoculated control under non-stress conditions.

The level of seedling toxicity was higher on media supplemented with Cd followed by $\mathrm{Cu}$ and it was relatively lower with Pb and Zn amended media. PGPR inoculation promoted significantly the early growth of the tested plants under metal stress. Indeed, under high metal conditions, the roots and shoots length of lettuce seedlings inoculated with the bacterial consortium were increased by 1.16 to 4.73 times and 1.2 to 3 times, respectively compared with noninoculated seeds (Fig. 1a, b). Similarly, increased growth of P.harmala seedlings grown in metal-contaminated media was observed after receiving the PGPR inoculants. The most pronounced beneficial effect on seedlings growth was observed in seeds exposed to the highest metal concentration. Roots growth of lettuce seedlings was completely inhibited in the uninoculated test containing 1, $0.5 \mathrm{Mm}$ of $\mathrm{Cu}$ and $\mathrm{Cd}$ while it reached about $93 \mathrm{~mm}$ when seeds were inoculated with PGPR inoculant (Fig. 1a). A significant reduction in roots and shoots length was also observed in uninoculated $P$. Harmala seedlings exposed to high levels of tested metals. As expected, inoculation of $P$. harmala seeds with PGPR under metal stress caused a remarkable increase in roots length by 1.28 to 6 times in comparison to uninoculated test. Shoots height was also improved by 8 times under $1 \mathrm{mM}$ of $\mathrm{Cd}$ and $13-\mathrm{fold}$ under $1 \mathrm{mM}$ of $\mathrm{Cu}$, 1.28 times under $2 \mathrm{Mm}$ of $\mathrm{Zn}$ and 1.39 - fold under $1 \mathrm{mM} \mathrm{Pb}$, compared to the uninoculated seeds (Fig. 1c and d).

Likewise, as with the metal test, PGPR treatments also increased root and shoot growth of the two studied species under salt stress induced by NaCl compared to uninoculated seedlings. Shoots of biopriming seedlings of $P$. harmala increased by 1.7 times when exposed to $100 \mathrm{mM} \mathrm{NaCl}$ and up to 1.9 and 2.5- fold under $115 \mathrm{Mm}$ and $125 \mathrm{mM} \mathrm{NaCl}$ in comparison to the uninoculated test. In lettuce seedlings case, bacterial consortium induced an increase in shoot growth by 4.5 -fold under $125 \mathrm{mM}$ of $\mathrm{NaCl}$ in comparison to seeds grown without bacterial inoculum. However, the positive effect of the bacterial consortium was most pronounced in roots than in shoots. A complete inhibition of root growth was observed for uninoculated lettuce seeds subjected to the highest level of salt stress $(125 \mathrm{mM})$, while a considerable improvement in its elongation (up to $0.8 \mathrm{~cm}$ ) occurred in when treated with PGPR. For $P$. harmala, roots length in PGPR inoculated seedlings was increased by 3.2 and 2.7 times compared to those without bacterial treatment when seeds were exposed to $125 \mathrm{mM}$ under $115 \mathrm{mM}$ of $\mathrm{NaCl}$, respectively (Fig. 3).

In this study, we have also outlined a more pronounced negative effect of metal stress and salinity on lettuce growth compared to $\mathrm{P}$. harmala. Indeed, the results showed that with high level of metals $(1,0.5 \mathrm{mM}$ of $\mathrm{Cd}$ and $\mathrm{Cu}$ and $2 \mathrm{mM}$ of $\mathrm{Zn}$ ) and salinity (125 mM NaCl) lettuce root elongation was completely inhibited, while P. harmala root growth was maintained under the same conditions and reached 43,26 and 70 mm in length when exposed to $0.5 \mathrm{mM}$ of $\mathrm{Cu}$, $0.5 \mathrm{mM}$ of $\mathrm{Cd}$ and $125 \mathrm{mM}$ of $\mathrm{NaCl}$, respectively (Fig. 4).

\section{Discussion}

\subsection{Screening of rhizobacteria for osmotic and metallic stress tolerant}

In this study, more than $56 \%$ of the tested rhizobacteria were able to tolerate high level of salinity (up to $10 \% \mathrm{NaCl}$ ). These findings may be attributed to the physicochemical conditions of the soils from which these strains were isolated. The climate conditions and high temperatures, particularly in summer in the Kettara mine lead to high evaporation and low infiltration in the region which constitute the main factors contributing to the salinization of land in this area (Boularbah et al. 2006a; El Khalil et al. 2008; El Hamiani et al. 2015; Benidire et al. 2020). In addition, as reported by previous work (Boularbah et al. 2006; Benidire et al. 2016), the soils of the kettara mine presented the high values of conductivity confirming the high mineralization of the soils in kettra mine area. Several studies reported that many bacteria isolated from salt conditions tolerate high concentration of $\mathrm{NaCl}, \mathrm{up} \mathrm{to} 10 \% \mathrm{NaCl}(\mathrm{Vardharajula}$ et al. 2011 ; Gururani et al. 2013; Armada et al. 2015) suggesting that natural salt environments seem to be a promising source of salinity tolerant bacteria able to alleviate salt stress in plants. In addition, among the strains tested in this study, the majority were found to be halotolerant since they could grow in media containing up to $10 \%$ of $\mathrm{NaCl}$ (Egamberdieva et al. 2009; Román-ponce et al. 2017; Khan et al. 2017; Raval et al. 2020).

High metal resistance was also observed, with more than $25 \%$ of the tested strains grown in media containing very high metal concentrations (up to $15 \mathrm{mM}$ $\mathrm{Zn}, 6 \mathrm{mM} \mathrm{Cd}, 9 \mathrm{mM} \mathrm{Pb}$ and $7 \mathrm{mM} \mathrm{Cu}$ ). Previous studies indicated that long-term exposure to metal contaminants can induce the activation of adaptive mechanisms in bacteria enabling them to reduce heavy metal toxicity, such as extracellular exclusion, biosorption, enzymatic detoxification or intracellular accumulation of metals ions in non-toxic form (Boularbah et al. 1992; Boularbah et al. 1993; Aboudrar et al. 2007; Gonzàlez et al. 2010; Ayangbenro and Babalola 2017; Liu et al. 2018; Mitra et al. 2018).

\subsection{Effect of salt and heavy metal stress on PGP activities}

In order to promote plant growth under unfavorable environmental conditions, the use of stress-tolerant rhizobacteria as a biofertilizers has received considerable attention in the recent years (Pandey 2009; Singh et al. 2015; Wang et al. 2019; Khan et al. 2017). These beneficial microorganisms improve plant performance by using various mechanisms, such as solubilization of soil nutrient, production of plant growth hormones and suppression of stress due to ethylene production (Ma et al. 2016; Din et al. 2019; Mahmoud et al. 2020). Moreover, due to their ability to improve plant metals tolerance and their capacity for metals immobilization in the soil, the use of PGPR for assisted phytoremediation of heavy metals contaminated soils has been widely studied (Aboudrar et al. 2013, Mitra et al. 2018; Pramanik et al. 2018; Din et al. 2019; Benidire et al. 2020). Several studies have also reported that plant-

Page $12 / 21$ 
microorganism interactions influence greatly and positively crops production under salt and drought conditions (Egamberdieva et al. 2009; Sandhya et al. 2010; Kang et al. 2014). In this study, we investigated the effect of salinity and metallic stress on PGPR performance. Our results showed that the PGP traits of the tested rhizobacteria, namely IAA, ammonia productions and P solubilization were strongly and negatively affected by the application of salt and metallic stress. Indeed, lower PGP activities were detected in strains cultivated under stress conditions compared to non-stressed ones except for siderophores production. This decrease in PGP traits indicates that under stressful conditions, rhizobacteria were actively involved on the metabolic mechanism leading to the control of abiotic stress than other metabolic process. The same results were reported by Armada et al. (2015) and Sandhya et al. (2010), where multiple PGP characteristics of rhizobacteria isolated from semi-arid environment decreased significantly when exposed to osmotic stress conditions. Likewise, Karthik et al. (2017) have reported a significant decrease of siderophores, AIA, ammonia, hydrolytics enzymes productions and phosphorus solubiliszation ability of rhizobacteria exposed to high concentration of Cr. However, this strain was able to rapidly promote the growth of the host plants under Cr-induced stress. Moreover, Deshwal et al. (2013) have suggested that heavy metals such as Pb, $\mathrm{Cr}$ and $\mathrm{Ni}$ reduced microbial biomass as well as IAA, hydrogen cyanide, siderophores productions and P-solubilization capacity of Pseudomonas strains isolated from potato rhizosphere. The present study has also outlined an increase in siderophores production of rhizobacteria when exposed to metallic stress, these findings suggest that these strains might use siderophores as a tool to reduce heavy metal toxicity by chelation process. Huo et al. (2020) have reported that under high concentrations of iron, selected siderophore-producing rhizobacteria Mesorhizobium panacihumi DCY 119T was able to reduce Fe-induced oxidative stress in Panax ginseng seedlings by binding toxic metals with siderophores and by activating the antioxidant system of plants.

PGPRs play an important role in improving plants performance under harsh environments, by producing various substances such as IAA and gibberellic acid which have already been identified to ameliorate seeds germination and plants growth in stressed conditions. It is also well known that IAA promote root architecture, stimulate lateral root development and increase root absorption surface, which improves nutrient and water uptake by plants under optimal and stressed conditions (Asghar et al. 2002; Rajkumar et al. 2006; Idriss et al. 2007; Kang et al. 2009; Román-ponce et al. 2017). The ability of tested rhizobacteria to grow under extreme conditions while keeping their PGP capacities, may be an interesting tool to be used to optimize the rehabilitation of area heavily contaminated by trace element or to enhance plant growth on metal contaminated, dry and saline environments (Updhyay et al. 2011; Durand et al. 2016; Ma et al. 2016; Ma et al. 2019).

\subsection{Bacterial response to salt and metallic stress}

Results of the osmotolerant rhizobacterial cells response to stress showed a huge increase in free amino-acids, proline and soluble sugars contents compared to the control. Indeed, these intrinsic metabolites confer to rhizobacteria a cellular adaptation to osmotic pressure, as an osmolyte function by maintaining high level of cell water status. Similar studies reported the same trend as response to osmotic stress (Sandhya et al. 2010; Gururani et al. 2012; Armada et al. 2015). Therefore, accumulation of osmolytes allows not only to improve water retention but also to alleviate oxidative damage and ameliorates membranes and enzymes stability under high level of drought and salt stress (Kang et al. 2014). In addition, soluble sugars serve as an energetic source for cells functioning, they are also used as substrate in biosynthesis procedures; contribute as tool for signal transduction regulation and as monitors of the gene expression (Sandhya et al. 2010).

Proteins contents increased significantly in all strains under heavy metal stress. This result may be related to the increase of antioxidant enzymes expression in microbial cells, which are used to maintain the normal redox status and to support the metabolic balance by eliminating the free radicals caused by metal stress (Armada et al. 2015). However, unlike other cellular compounds, a very important decrease in protein contents in all strains while exposed to high salinity was observed, which can be considered as an indicator of bacterial cells toxicity due to the osmotic stress (Vardharajula et al. 2011).Protein hydrolysis has been reported to cause an increase in free amino acids involved in cellular osmotic adjustment; whereas proteins themselves are used for polysaccharides production (Vardharajula et al. 2011; lqbal et al. 2013).Indeed, in accordance with these findings, in our study an increase in EPS production by all bacteria was observed after their exposure to salt and heavy metal stress compared to non-stressed conditions.EPS are important components involved in bacterial biofilm formation that helps maintain hydration of the microenvironment around bacterial cells and protect them from desiccation (Becker et al, 1998; Zhu et al, 2018; Zhang et al, 2020). It has also been reported that EPS can bind toxic $\mathrm{Na}^{+}$cations, reducing their toxic effect on cells and alleviate osmotic stress due to salinity (Ashraf et al. 2004; Upadhyay et al. 2011; Zhu et al. 2018). Moreover, Kalpana et al. (2018) has reported that microbial tolerance to heavy metals such as $\mathrm{Cu}, \mathrm{Zn}, \mathrm{Pb}$ and $\mathrm{Cd}$ is strongly related to the polysaccharides adsorption properties. In fact, due to their negatively charged hydroxyl and phosphoryl groups, these polymeric carbohydrates can reduce metals mobility and therefore increases bacterial cells viability (Boularbah et al. 1992; González et al. 2010). Our results are in line with previous studies where an increase in exopolysaccharides production was also recorded in bacteria in response to drought and salt stress (Qurashi et al. 2012; Tewari and Arora 2014; Din et al. 2019).

\subsection{Effect of PGPR inoculation on seedlings growth under metal and salt stress}

It is well known that plants candidates for phytostabilization should be metal-tolerant species which exclude heavy metals from the root apex or limit the accumulation only in their roots tissues. Thus, in addition to their high metal tolerance capacity, the root system of these plants should be deeper with a large surface area to provide a high nutrient environment and to prevent heavy metal spread by erosion process over the long term (Zhang et al. 2012 ; Zou et al. 2012; Testiati et al. 2013; Shackira 2017 a, b). In this study, we investigated the root elongation considering this parameter as a tool that can provide us with additional information on the effectiveness of the interaction of plant with the four selected PGPR strains under stressed conditions. Our results showed that, in the absence of metal stress, the mixture of the used rhizobacteria can stimulate significantly root elongation compared to non-inoculated seedlings. Furthermore, the beneficial effect is well observed when the growing media was amended with metal salts, particularly at highest concentration ( $0.5 \mathrm{mM}$ and $1 \mathrm{mM}$ of $\mathrm{Cd}$ and $\mathrm{Cu}$ and with $2 \mathrm{mM}$ of $\mathrm{Zn}$ ). Under metal stress and without bacterial treatment, lettuce seeds were able to germinate but the root growth was completely inhibited few days after emergence. The four rhizobacteria used in this mixture have been characterized for their multi-metals' resistance to higher concentrations of $\mathrm{Cu}$ (up to $6 \mathrm{mM}$ ), $\mathrm{Pb}$ (up to $7 \mathrm{mM}$ ), $\mathrm{Cd}$ (up to $5 \mathrm{mM}$ ) and $\mathrm{Zn}$ (up to $10 \mathrm{mM}$ ). Moreover, they showed a high tolerance to salinity (up to $10 \% \mathrm{NaCl}$ ) and maintained their plant growth promoting traits even under high concentrations of $\mathrm{NaCl}$. In previous studies, several bacterial strains 
belonging to the genera Pseudomonas spp. characterized by their high tolerance to $\mathrm{Cd}$, have also been reported to have a better capacity to stimulate plants growth under salt, drought and metallic tress (Gonzàlez et al. 2010; Ma et al. 2016; Zhu et al. 2018). Similarly, a strain isolated from metal contaminated rice rhizosphere and identified as Enterobacter sp. showed a great ability to promote rice seedling growth under Cd-induced stress by producing PGP compounds and contributed as well in reducing the oxidative damage induced by high metal concentration (Mitra et al. 2018). Nascimento et al. (2012) and Verma et al. (2013) reported a significant improvement in the growth parameters of chickpea plants inoculated with Mesorhizobium sp. compared to uninoculated control grown under environmental constraints.

In this study, the positive effect of the studied bioinoculants on root elongation both under control and stressed conditions could be explained by their ions adsorption capacity and metals accumulation in active cells leading to the reduction of metal toxicity (Boularbah et al. 1992; Boularbah et al. 1993; Ayangbenro and Babalola 2017; Liu et al. 2018). Enhanced growth of inoculated seeds could be attributed also to the ability of rhizobacteria to synthesize growth stimulating phytohormones, which can affect enzymes functioning such as a amylase that can ameliorate starch assimilation during the germination process and therefore promote early seed germination (Bharathi et al. 2004; González et al. 2010; Ashwini et al. 2011). The phytohormone IAA produced by PGPR can also help in increasing root surface area, root formation and lateral root growth (Román-Ponce et al. 2017). In addition, bacterial exopolysaccharides can contribute on root growth stimulation, by protecting seeds and seedling roots against $\mathrm{Na}^{+}$and toxic metal ions through forming a polymer matrix around seeds and roots (Ashraf et al. 2004; Upadhyay et al. 2011; Zhu et al. 2018; Din et al. 2019).

The results clearly showed that P. harmala seeds sampled from Kettara mine site heavily polluted with metals are more tolerant to metal and salinity than lettuce seeds. These results might be explained by the characteristics of the growing environment of this plant. Indeed, it has been demonstrated that at the P. harmala's sampling site, the soils were highly saline and contain high concentrations of several heavy metals, especially copper and zinc (Benidire et al. 2016; El Khalil et al. 2008; El Hamiani et al. 2015). This confirms that, throughout their long-term exposure to hostile conditions in the mining region, the seeds evolved mechanisms more suited for their survival under the stressed conditions.

\section{Conclusions}

In this study, most of the tested rhizobacteria displayed a high level of multi-heavy metal resistance. In addition, among the 29 tested strains, 16 strains could be classified as halotolerant bacteria due to their ability to grow in the presence of $10 \% \mathrm{NaCl}$. The adaptation mechanisms used by these rhizobacteria in response to osmotic stress have been highlighted, such as the accumulation of osmolytes (sugars, amino acids and proline) and the production of exopolysaccharides. Besides their high adaptation to adverse conditions, the studied strains seem to maintain a relative high PGP capacity even under stress conditions.

In this study, the beneficial effects of osmotolerant PGPR strains on plants subjected to metal or salt stress was confirmed by an in vitro test. The results of this assay showed that inoculation of seeds with the selected strains promote a significant stimulation of lettuce and wild rue seedlings growth, compared to the control. Besides, the seedling could withstand metal and salt stress more efficiently in presence of the bacterial mixture, as indicated by increases in shoots and roots growth of inoculated stressed plants in comparison to uninoculated ones, this study revealed clearly that the consortium of PGPR used can be used as toolto improve crop productivity in stressed condition. Therefore, the bacterial consortium studied in this paper can be used as a potential bioinoculant to assist phytoremediation of degraded soil in arid and semi-arid areas. The present study was focused on the effect of salinity and metallic stress on the PGP traits and some bacterial physiology aspects. Other studies related to drought stress and acidity will help understanding the effect of abiotics stresses on the bacterial physiology and PGP traits. Moreover, the effectiveness of consortium of abiotic stress tolerant rhizobacteria as tools helping the establishment of plants on the degraded soils should be tested in pots and under field conditions.

\section{Declarations}

\section{Acknowledgments}

This study was financially supported by the Convention de coopération CNRST-Morocco/FCT-Portugal and the Centre National de Recherche Scientifique et Techniques [grant no. PPR 22/2015]

\section{Ethics approval and consent to participate}

Not applicable

\section{Consent for publication}

Not applicable

\section{Availability of data and materials}

The data that support the findings of this study are available from the corresponding author upon reasonable request.

\section{Competing interests}

The authors declare that they have no known competing financial interests or personal relationships that could have appeared to influence the work reported in this paper

\section{Funding}


All sources of funding for the research reported are declared

\section{Authors' contributions}

Prof. Boularbah Ali contributed with the idea of the study, and the correction of the paper. Madline Atika and Benidire Leila designed the study. Madline Atika carried out also the Laboratory experiments, analysed the data, and writing the manuscript.

\section{References}

1. Aboudrar W, Schwartz C, Benizri E, Morel J L and Boularbah A (2007) Soil microbial diversity as affected by the rhizosphere of the hyperaccumulator Thlaspi caerulescens under natural conditions. International journal of phytoremediation, 9(1), 41-52.https://doi.org/10.1080/15226510601139417.

2. Aboudrar W, Schwartz C, Morel JL, and Boularbah A (2013) Effect of nickel-resistant rhizosphere bacteria on the uptake of nickel by the hyperaccumulator Noccaea caerulescens under controlled conditions. Journal of Soils and Sediments, 13(3), 501-507.

3. Adriano DC, Wenzel WW, Vangronsveld J and Bolan NS (2004) Role of assisted natural remediation in environmental cleanup. Geoderma, 122: 121-142. https://doi.org/10.1016/j.geoderma.2004.01.003

4. Adriano DC (2001) Trace elements in terrestrial environments: biogeochemistry, biovailability and risks of metals. 2nd Editions Spring- verlag, New York, Berlin, Heidelberg.

5. Alam R, Ahmed Z, Howladar MF (2019) Evaluation of heavy metal contamination in water, soil and plant around the open land fill site Mogla Bazar in Sylhet, Bangladesh. Ground water for Sustainable Development, 100311. https://doi.org/10.1016/j.gsd.2019.100311

6. Armada E, Barea JM, Castillo P, Roldán A. and Azcón R (2015) Characterization and management of autochthonous bacterial strains from semiarid soils of Spain and their interactions with fermented agrowastes to improve drought tolerance in native shrub species. Applied Soil Ecology, 96, $306-318$. http://dx.doi.org/10.1016/j.apsoil.2015.08.008

7. Arora NK, Tewari S, Singh S, Lal N and Maheshwari DK (2012) PGPR for protection of plant health under saline conditions. In Bacteria in agrobiology: stress management (pp. 239-258).https://doi.org/10.1007/978-3-662-45795-5_12

8. Asghar HN, Zahir ZA, Arshad M, Khaliq K (2002) Relationship between in vitro production of auxins by rhizobacteria and their growth-promoting activities in Brassica juncea L. BiolFertil Soils. 35:231-237. https://doi.org/10.1007/s00374-002-0462-8

9. Ashraf M, Berge SH and Mahmood OT (2004) Inoculating wheat seedlings with exopolysaccharides producing bacteria restricts sodium uptake and stimulates plant growth under salt stress. Biol. Fer. Soils, 40: 157-162. https://doi.org/10.1007/s00374-004-0766-y

10. AshwiniK, Kumar G, Karthik L and Bhaskara Rao KV (2011) Optimization, production and partial purification of extracellular a-amylase from Bacillus sp. marini. Arch. Appl. Sci. Res. 3, 33-42.

11. Ayangbenro AS, and Babalola $O 0$ (2017) A New Strategy for Heavy Metal Polluted Environments: A Review of Microbial Biosorbents Inter. J. Env. Res. Pub. Heal. New strategy for heavy metal polluted environments: a review of microbial biosorbents. Int. J. Environ. Res. Publ. Health $14,94$. https://doi.org/10.3390/ijerph14010094

12. Bates LS, Waldren RP, and Teare ID (1973) Rapid determination of free proline for water-stress studies. Plant and soil, 39(1), $205-207$. https://www.jstor.org/stable/42932378

13. Becker A, Katzen F, Pühler A, and lelpi L (1998) Xanthan gum biosynthesis and application: A biochemical/genetic perspective. Applied Microbiology and Biotechnology, 50(2), 145-152. https://doi.org/10.1007/s002530051269

14. Benidire L, Pereira SIA, Castro PML, Boularbah A (2016) Assessment of plant growth promoting bacterial populations in the rhizosphere of metallophytes from the Kettara mine, Marrakech. Environmental Science and Pollution Research, 23: 21751-21765. https://doi.org/10.1007/s11356-0167378-6

15. Benidire L, Madline A, Pereira, SIA, Castro, PML, and Boularbah A (2020) Synergistic effect of organo-mineral amendments and plant growth-promoting rhizobacteria (PGPR) on the establishment of vegetation cover and amelioration of mine tailings. Chemosphere, $262,127803$. https://doi.org/10.1016/j.chemosphere.2020.127803

16. Bharathi R, Vivekananthan R, Harish S, Ramanathan A, and Samiyappan R (2004) Rhizobacteria-based bio-formulations for the management of fruit rot infection in chillies. Crop Protect. 23 (9), 835-843. https://doi.org/10.1016/j.cropro.2004.01.007

17. Boularbah A, Morel JL, Bitton G, and Guckert A (1992) Cadmium biosorption and toxicity to six cadmium-resistant gram-positive bacteria isolated from contaminated soil. Environmental Toxicology and Water Quality, 7(3), 237-246.

18. Boularbah A, Morel J L, and Lefebvre G (1993) Altérations morphologiques des cellules de Bacillus brevis par le cadmium. CR Acad Sci (Paris), 316, 307313.

19. Boularbah A, Schwartz C, Bitton G and Morel JL (2006a) Heavy metal contamination from mining sites in South Morocco: 1 . Use of a biotest to assess metal toxicity of tailings and soils. Chemosphere, 63: 802-810

20. Boularbah A, Schwartz C, Bitton G, Aboudrar W, Ouhammou A and Morel JL (2006b) Heavy metal contamination from mining sites in South Morocco: 2. Assessment of metal accumulation and toxicity in plants. Chemosphere, 63: 811-817. https://doi.org/10.1016/j.chemosphere.2005.07.079

21. Bradford M (1976) A rapid and sensitive method for the quantitation of microgram quantities of protein utilizing the principle of protein-dye binding. Anal Biochem.72:248_258.

22. Cappuccino JC, and Sherman N (1992) Negative staining. In: Cappuccino JC, Sherman N (eds) Microbiology: a laboratory manual. Benjamin/ Cummings, Pub Co, Redwood City, pp. 125-179 
23. Chakraborty U, Chakraborty BN, Chakraborty AP, and Dey PL (2013) Water stress amelioration and plant growth promotion in wheat plants by osmotic stress tolerant bacteria. World Journal of Microbiology and Biotechnology, 29(5), 789-803. https://doi.org/10.1007/s11274-012-1234-8

24. Conesa HM, Robinson BH, Schullin R, Nowack B (2007) Growth of Lygeum spartum in acid mine tailings: response of plants developed from seedlings, rhizomes, and at field conditions. Environ Pollut145:700-707. https://doi.org/10.1016/j.envpol.2006.06.002

25. Coniglio A, Mora V, Puente M, and Cassán F (2019) Azospirillum as Biofertilizer for Sustainable Agriculture: Azospirillum brasilense AZ39 as a Model of PGPR and Field Traceability. In Microbial Probiotics for Agricultural Systems (pp.45-70).https://doi.org/10.1007/978-3-030-17597-9_4

26. Craw D, Rufaut C, Haffert L, Paterson L (2007) Plant colonization and arsenic uptake on high arsenic mine wastes, New Zealand. Water Air SoilPollut179:351-364.https://doi.org/10.1007/s11270-006-9238-3

27. Cui H, Li H, Zhang S, Yi Q, Zhou J, Fang G, and Zhou J (2020) Bioavailability and mobility of copper and cadmium in polluted soil after phytostabilization using different plants aided by limestone. Chemosphere, 242, 125252. https://doi.org/10.1016/j.chemosphere.2019.125252

28. Cunningham SD, and Berti WWR (2000) Phytoextraction and phytostabilization: technical, economic, and regulatory considerations of the soil-lead issue. In: Terry N, Banuelos G (eds) Phytoremediation of contaminated soil and water. CRC Press LLC, Boca Raton.

http://dx.doi.org/10.15666/aeer/1703_61296149

29. Dary M, Chamber-Pérez MA, Palomares AJ, and Pajuelo E (2010) “In situ” phytostabilisation of heavy metal polluted soils using Lupinus luteus inoculated with metal resistant plant-growth promoting rhizobacteria. Journal of Hazardous Materials, 177(1), 323330.https://doi.org/10.1016/j.jhazmat.2009.12.035

30. Deshwal VK, and Kumar P (2013) Effect of Heavy metals on Growth and PGPR activity of Pseudomonads. Journal of Academia and Industrial Research (JAIR), 2(5), 286.

31. Din BU, Sarfraz S, Xia Y, Kamran MA, Javed MT, Sultan T, and Chaudhary HJ (2019) Mechanistic elucidation of germination potential and growth of wheat inoculated with exopolysaccharide and ACC-deaminase producing Bacillus strains under induced salinity stress. Ecotoxicology and environmental safety, 183, 109466.https://doi.org/10.1016/j.ecoenv.2019.109466

32. Dubois M, Gilles KA, Hamilton JK,Rebers PA, Smith F (1956) Colorimetric methods for determination of sugars of related substances.Anal Chem. 28:350_356.

33. Durand A, Piutti S, Rue M, Morel JL, Echevarria G and Benizri E (2016) Improving nickel phytoextraction by co-cropping hyperaccumulator plants inoculated by plant growth promoting rhizobacteria. Plant and soil, 399(1-2), 179-192.URL: http://www.jstor.com/stable/43872545

34. Egamberdieva D, and Adesemoye AO (2016) Improvement of crop protection and yield in hostile agroecological conditions with PGPR-based biofertilizer formulations. In Bioformulations: For sustainable agriculture (pp. 199-211).

35. Egamberdieva D, and Kucharova Z (2009) Selection for root colonising bacteria stimulating wheat growth in saline soils. Biology and fertility of soils, 45(6), 563-571.https://doi.org/10.1007/s00374-009-0366-y

36. El Amari K, Valera P, Hibti M, Pretti S, Marcello A, and Essarraj S (2014) Impact of mine tailings on surrounding soils and ground water: Case of Kettaraold mine, Morocco. Journal of African Earth Sciences, 100, 437-449.http://dx.doi.org/10.1016/j.jafrearsci.2014.07.017

37. El Hamiani O, El Khalil H, Lounate K, Sirguey C, Hafidi M, Bitton G, Schwartz C, Boularbah A (2010) Toxicity assessment of garden soils in the vicinity of mining areas in southern Morocco. J Hazard Mater 177:755-761. https://doi.org/10.1016/j.jhazmat.2009.12.096

38. El Hamiani O, El Khalil H, Sirguey C, Ouhammou A, Bitton G, Schwartz C, and Boularbah A (2015) Metal Concentrations in Plants from Mining Areas in South Morocco: Health Risks Assessment of Consumption of Edible and Aromatic Plants. CLEAN-Soil, Air, Water, 43(3), 399-407.

https://doi.org/10.1002/clen.201300318

39. ElKhalil H, El Hamiani O, Bitton G, Ouazzani N and Boularbah A (2008) Heavy metal contamination from mining sites in South Morocco: 3 . Metal toxicity of soil runoff and groundwater. Environmental Monitoring and Assessment, 136:147-160. https://doi.org/10.1007/s10661-007-9671-9

40. Ghafoor A, Hay ID, and Rehm BH (2011) Role of exopolysaccharides in Pseudomonas aeruginosa biofilm formation and architecture. Applied and environmental microbiology, 77(15), 5238-5246. https://doi.org/10.1128/AEM.00637-11

41. González AG, Shirokova LS, Pokrovsky OS, Emnova EE, Martínez RE, Santana-Casiano JM, and Pokrovski GS (2010) Adsorption of copper on Pseudomonas aureofaciens: protective role of surface exopolysaccharides. Journal of colloid and interface science, 350(1), 305-314.

https://doi.org/10.1016/j.jcis.2010.06.020

42. Gordon SA, Weber RP (1951) Colorimetric estimation of indole acetic acid. Plant Physiol 26:192-195

43. Gururani MA, Upadhyaya CP, Baskar V, Venkatesh J, Nookaraju A, and Park SW (2013) Plant growth-promoting rhizobacteria enhance abiotic stress tolerance in Solanum tuberosum through inducing changes in the expression of ROS-scavenging enzymes and improved photosynthetic performance. Journal of Plant Growth Regulation, 32(2), 245-258. https://doi.org/10.1007/s00344-012-9292-6

44. Huo Y, Kang JP, Ahn JC, Kim YJ, Piao CH, Yang DU and Yang DC (2020) Siderophore-producing rhizobacteria reduce heavy metal-induced oxidative stress in Panax ginseng Meyer. Journal of Ginseng Research. https://doi.org/10.1016/j.jgr.2019.12.008

45. Ibiene AA, Agogbua JU, Okonko IO and Nwachi GN (2012) Plant growth promoting rhizobacteria (PGPR) as biofertilizer: Effect on growth of Lycopersicumesculentus. Journal of American Science, 8(2), 318-324.http://www.americanscience.org

46. Idriss EE, Iglesias DJ, Talon M, Borriss R (2007) Tryptophan dependent production of indole-3 acetic acid (IAA) affects level of plant growth promotion by Bacillusamyloliquefaciens FZB42. Mol Plant Microbe Interact 20:619-626. https://doi.org/10.1094/MPMI-20-6-0619

47. Iqbal M, and Ashraf M (2013) Gibberellic acid mediated induction of salt tolerance in wheat plants: growth, ionic partitioning, photosynthesis, yield and hormonal homeostasis. Environ Exp Bot. 86:76-85. https://doi.org/10.1016/j.envexpbot.2010.06.002

Page $16 / 21$ 
48. Jiang B, Adebayo A, Jia J, Xing Y, Deng S, Guo L and Zhang D (2019) Impacts of heavy metals and soil properties at a Nigerian e-waste site on soil microbial community. Journal of hazardous materials, 362, 187-195. https://doi.org/10.1016/j.jhazmat.2018.08.060

49. Kabata-Pendias A, and Pendias H (2001) Trace elements in soils and plants. 3ème Edition CRC Press Boca Raton, London, New-York, Washington D.C

50. Kalpana R, Angelaalincy MJ, Kamatchirajan BV, Vasantha VS, Ashokkumar B, Ganesh V and Varalakshmi P (2018) Exopolysaccharide from Bacillus cereus VK1: Enhancement, characterization and its potential application in heavy metal removal. Colloids and Surfaces B: Biointerfaces, 171, $327-334$. https://doi.org/10.1016/j.colsurfb.2018.07.043

51. Kang SM, Joo GJ, Hamayun M, Shin DH, Kim H, Hong JK, and Lee IJ (2009) Gibberelline production and phosphate solubilization by newly isolated strain of Acinetobacter calcoaceticus and its effect on plant growth. Biotechnology letters, 31 (2), 277-281.https://doi.org/ 10.1007/s10529-008-9867-2

52. Kang SM, Khan AL, Waqas M, You YH, Kim JH, Kim JG and Lee IJ (2014) Plant growth-promoting rhizobacteria reduce adverse effects of salinity and osmotic stress by regulating phytohormones and antioxidants in Cucumissativus. Journal of Plant Interactions, 9(1), 673682.https://doi.org/10.1080/17429145.2014.894587

53. Khan MY, Zahir ZA, Asghar HN, and Waraich EA (2017) Preliminary investigations on selection of synergistic halotolerant plant growth promoting rhizobacteria for inducing salinity tolerance in wheat. Pak J Bot, 49(4), 1541-1551.

54. Khan N, Bano A, and Zandi P (2018) Effects of exogenously applied plant growth regulators in combination with PGPR on the physiology and root growth of chickpea (Cicer arietinum) and their role in drought tolerance. Journal of plant interactions, 13(1), $239-247$. https://doi.org/10.1080/17429145.2018.1471527

55. Karthik C and Arulselvi PI (2017) Biotoxic effect of chromium (VI) on plant growth-promoting traits of novel Cellulosi microbium funkei strain AR8 isolated from Phaseolus vulgaris rhizosphere. Geomicrobiology Journal, 34(5), 434-442. http://dx.doi.org/10.1080/01490451.2016.1219429

56. Lin Y, Ye Y, Hu Y, Shi H (2019) The variation in microbial community structure under different heavy metal contamination levels in paddy soils. Ecotoxicology and environmental safety, 180, 557-564. https://doi.org/10.1016/j.ecoenv.2019.05.057

57. Liu Z, Lu B, Xiao H, Liu D, Li X, Wang LA and Nagorskaya L (2019) Effect of mixed solutions of heavy metal eluents on soil fertility and microorganisms. Environmental Pollution, 254, 112968. https://doi.org/10.1016/j.envpol.2019.112968

58. Liu YL, Tie BQ, Li YX, Lei M, Wei XD, Liu XL, Du HH (2018) Inoculation of soil with Cd-resistant bacterium Delftia sp. B9 reduces Cd accumulation in rice (Oryza sativa L.) grains. Ecotox. Environ. Safe. 163, 223-229.

59. Ma Y, Rajkumar M, Oliveira RS, Zhang C and Freitas H (2019) Potential of plant beneficial bacteria and arbuscular mycorrhizal fungi in phytoremediation of metal-contaminated saline soils. Journal of hazardous materials, 379, 120813. https://doi.org/10.1016/j.jhazmat.2019.120813

60. Ma Y, Rajkumar M, Zhang C and Freitas H (2016) Inoculation of Brassica oxyrrhina with plant growth promoting bacteria for the improvement of heavy metal phytoremediation under drought conditions. Journal of hazardous materials, 320, 36-44. https://doi.org/10.1016/j.jhazmat.2016.08.009

61. Mahmoud OMB, Hidri R, Talbi-Zribi O, Taamalli W, Abdelly C and Djébali N (2020) Auxin and proline producing rhizobacteria mitigate salt-induced growth inhibition of barley plants by enhancing water and nutrient status. South African Journal of Botany, 128, $209-217$. https://doi.org/10.1016/j.sajb.2019.10.023

62. Mitra S, Pramanik K, Sarkar A, Ghosh PK, Soren T and Maiti TK (2018) Bioaccumulation of cadmium by Enterobacter sp. and enhancement of rice seedling growth under cadmium stress. Ecotoxicology and environmental safety, 156, 183-196. https://doi.org/10.1016/j.ecoenv.2018.03.001

63. Nascimento FX, Brígido C, Glick BR, Oliveira S and Alho L (2012) Mesorhizobium ciceri LMS-1 expressing an exogenous 1-aminocyclopropane-1carboxylate (ACC) deaminase increases its nodulation abilities and chickpea plant resistance to soil constraints. Lett. Appl. Microbiol.

DOI: 10.1111/j.1472-765X.2012.03251.x

64. Nautiyal V (1999) An efficient microbiological growth medium for screening phosphate solubilizing microorganisms. MicrobiolLett 170:265-270. https://doi.org/10.1111/j.1574 6968.1999.tb13383.x

65. Ondobo ML, Effa PO, Manga JN, Djoko JC K and Djocgoue PF (2017) Breeding of parental and tolerant hybrids of Theobroma cacao L. to Phytophthora megakarya Bras. And Griff. International Journal of Plant Physiology and Biochemistry, 9(2), 9-21. https://doi.org/10.5897/IJPPB2017.0262

66. Pandey A (2009) Bacillus subtilis NRRL B-30408 inoculation enhances the symbiotic efficiency of Lens esculenta Moench at a Himalayan location. J Plant Nutr Soil, 172(1), 134-139. https://doi.org/10.1002/jpln.200800153

67. Pandey N, and Bhatt R (2015) Arsenic resistance and accumulation by two bacteria isolated from a natural arsenic contaminated site. Journal of basic microbiology, 55(11), 1275-1286. https://doi.org/10.1002/jobm.201400723

68. Pavel PB, Puschenreiter M, Wenzel WW, Diacu E and Barbu C. H (2014) Aided phytostabilization using Miscanthus sinensis giganteus on heavy metalcontaminated soils. Science of the Total Environment, 479, 125-131.https://doi.org/10.1016/j.scitotenv.2014.01.097

69. Prabu PC (2009) Impact of heavy metal contamination of Akaki River of Ethiopia on soil and metal toxicity on cultivated vegetable crops. Electronic Journal of Environmental, Agricultural \& Food Chemistry, 8(9).

70. Pramanik K, Mitra S, Sarkar A, Soren T and Maiti T. K (2018) Characterization of a $\mathrm{Cd}^{2+}$ resistant plant growth promoting rhizobacterium (Enterobacter sp.) and its effects on rice seedling growth promotion under $\mathrm{Cd}^{2+}$ stress in vitro. Agriculture and Natural Resources, 52(3), $215-221$. https://doi.org/10.1016/j.anres.2018.09.007

71. Qurashi AW and Sabri A. N (2012) Bacterial exopolysaccharide and biofilm formation stimulate chickpea growth and soil aggregation under salt stress. Brazilian Journal of Microbiology, 43(3), 1183-1191. https://doi.org/10.1590/S1517-838220120003000046

72. Rajkumar M, Nagendran R, Lee K J, Lee W H and Kim S Z (2006) Influence of plant growth promoting bacteria and Cr ${ }^{6+}$ onthe growth of Indian mustard. Chemosphere. 62: 741-748. https://doi.org/10.1016/j.chemosphere.2005.04.117

Page $17 / 21$ 
73. Raval V. H and Saraf M (2020) Biosynthesis and purification of indole-3-acetic acid by halotolerant rhizobacteria isolated from Little Runn of Kachchh. Biocatalysis and Agricultural Biotechnology, 23, 101435. https://doi.org/10.1016/j.bcab.2019.101435

74. Rizvi A and Khan MS (2018) Heavy metal induced oxidative damage and root morphology alterations of maize (Zea mays L.) plants and stress mitigation by metal tolerant nitrogen fixing Azotobacter chroococcum. Ecotoxicology and environmental safety, 157, 9-20.

https://doi.org/10.1016/j.ecoenv.2018.03.063

75. Román-ponce B, Reza-vázquez DM, Gutiérrez-paredes S, María de Jesús DE, Maldonado hernández J, Bahena-osorio Y and Vásquez-murrieta MS (2017) Plant growth-promoting traits in rhizobacteria of heavy metal-resistant plants and their effects on Brassica nigra seed germination. Pedosphere, 27(3), 511-526. https://doi.org/10.1016/S1002-0160(17)60347-3

76. Sandhya VS KZ, Ali SZ, Grover M, Reddy G and Venkateswarlu B (2010) Effect of plant growth promoting Pseudomonas spp. on compatible solutes, antioxidant status and plant growth of maize under drought stress. Plant Growth Regulation, 62(1), 21-30. https://doi.org/10.1080/17429145.2010.535178

77. Schwy B, Neilands JB (1987) Universal chemical assay for the detectionand determination of siderophores. Anal Biochem 160:47-56. https://doi.org/10.1016/0003-2697(87)90612-9

78. Shackira AM, and Puthur JT (2017a) Enhanced phytostabilization of cadmium by a halophyte Acanthus ilicifolius L. International journal of phytoremediation, 19(4), 319-326. https://doi.org/10.1080/15226514.2016.1225284

79. Shackira AM, Puthur JT and Salim E. N (2017 b) Acanthu silicifolius L. a promising candidate for phytostabilization of zinc. Environmental monitoring and assessment, 189 (6), 282. https://doi.org/10.1007/s10661-017-6001-8

80. Singh RP, Jha P, and Jha PN (2015) The plant-growth-promoting bacterium Klebsiella sp. SBP-8 confers induced systemic tolerance in wheat (Triticum aestivum) under salt stress. Journal of plant physiology, 184, 57-67. https://doi.org/10.1016/j.jplph.2015.07.002

81. Testiati E, Parinet J, Massiani C, Laffont-Schwob I, Rabier J, Pfeifer HR and Prudent P (2013) Trace metal and metalloid contamination levels in soils and in two native plant species of a former industrial site: evaluation of the phytostabilization potential. Journal of Hazardous Materials, 248, 131141.https://doi.org/10.1016/j.jhazmat.2012.12.039

82. Tewari S and Arora NK (2014) Multifunctional exopolysaccharides from Pseudomonas aeruginosa PF23 involved in plant growth stimulation, biocontrol and stress amelioration in sunflower under saline conditions. Current microbiology, 69(4), 484-494. https://doi.org/ 10.1007/s00284-014-0612-x

83. Tripura C, Sashidhar B and Podile AR (2007) Ethyl Methane sulfonate Mutagenesis Enhanced Mineral Phosphate Solubilization by GroundnutAssociated Serratia marcescens GPS 5. Current microbiology, 54(2), 79-84. https://doi.org/10.1007/s00284-005-0334-1

84. Upadhyay SK, Singh JS, and Singh DP (2011) Exopolysaccharide-producing plant growth promoting rhizobacteria under salinity condition. Pedosphere, 21(2), 214-222. https://doi.org/10.1016/S1002-0160(11)60120-3

85. Vardharajula S, Zulfikar Ali S, Grover M, Reddy G and Bandi V (2011) Drought-tolerant plant growth promoting Bacillus spp.: effect on growth, osmolytes, and antioxidant status of maize under drought stress. Journal of Plant Interactions, 6(1), 1-14. https://doi.org/10.1080/17429145.2010.535178

86. Verma JP, Yadav J, Tiwari KN and Kumar A (2013) Effect of indigenous Mesorhizobium spp. and plant growth promoting rhizobacteria on yields and nutrients uptake of chickpea (Cicerarietinum L.) under sustainable agriculture. Ecological Engineering, 51, $282-286$.

87. Vurukonda SS KP, Vardharajula S, Shrivastava M and SkZ A (2016) Multifunctional Pseudomonas putida strain FBKV2 from arid rhizosphere soil and its growth promotional effects on maize under drought stress. Rhizosphere, 1, 4-13. https://doi.org/10.1016/j.rhisph.2016.07.005

88. Wang C, Liu Z, Huang Y, Zhang Y, Wang X and Hu Z (2019) Cadmium-resistant rhizobacterium Bacillus cereus M4 promotes the growth and reduces cadmium accumulation in rice (Oryza sativa L.). Environmental Toxicology and Pharmacology, 72, 103265. https://doi.org/10.1016/j.etap.2019.103265

89. Watanabe FS and Olsen S. R (1965) Test of an ascorbic acid method for determining phosphorus in water and $\mathrm{NaHCO}_{3}$ extracts from soil 1 . Soil Science Society of America Journal, 29(6), 677-678. http://dx.doi.org/10.2136/sssaj1965.03615995002900060025x

90. Whiting SN, de Souza MP and Terry N (2001) Rhizosphere bacteria mobilize Zn for hyperaccumulation by Thlaspi caerulescens. Environmental Science and Technology, 35(15), 3144-3150. https://doi.org/10.1021/es001938v

91. Zhang S, Li T, Huang H, Zou T, Zhang X, Yu H and Wang Y (2012) Cd accumulation and phytostabilization potential of dominant plants surrounding mining tailings. Environmental Science and Pollution Research, 19(9), 3879-3888. https://doi.org/10.1007/s11356-012-1060-4

92. Zhang WP, Zhao YJ, Zhao ZW, Cheng X and Li KT (2020) Structural characterization and induced copper stress resistance in rice of exopolysaccharides from Lactobacillus plantarum LPC-1. International journal of biological macromolecules, 152, 1077-1088.

https://doi.org/10.1016/j.ijbiomac.2019.10.195

93. Zhu W, Wang Y, Yan F, Song R, Li Z, Li Y and Song B (2018) Physical and chemical properties, percutaneous absorption-promoting effects of exopolysaccharide produced by Bacillus atrophaeus WYZ strain. Carbohydrate polymers, 192, 52-60. https://doi.org/10.1016/j.carbpol.2018.03.063

94. Zou T, Li T, Zhang X, Yu H, and Huang H (2012) Lead accumulation and phytostabilization potential of dominant plant species growing in a lead-zinc mine tailing. Environmental Earth Sciences, 65(3), 621-630. https://doi.org/10.1007/s12665-017-6894-0

\section{Figures}




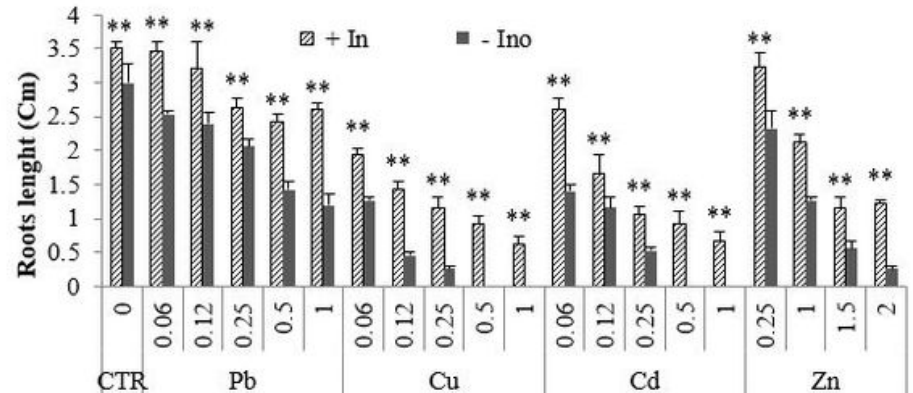

a

Metallic concentrations (mM)

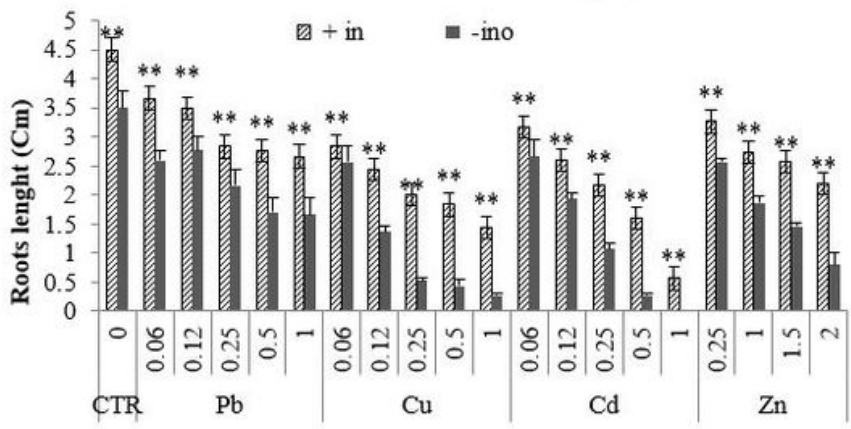

c

Metallic concentrations (mM)

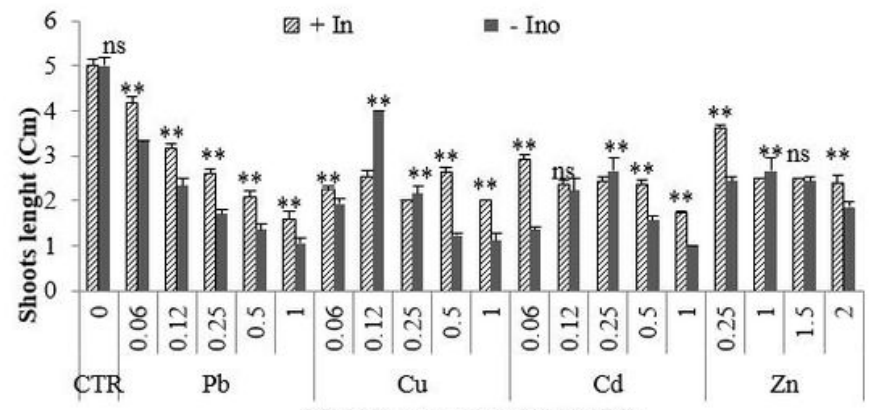

Metallic concentrations (mM)

b

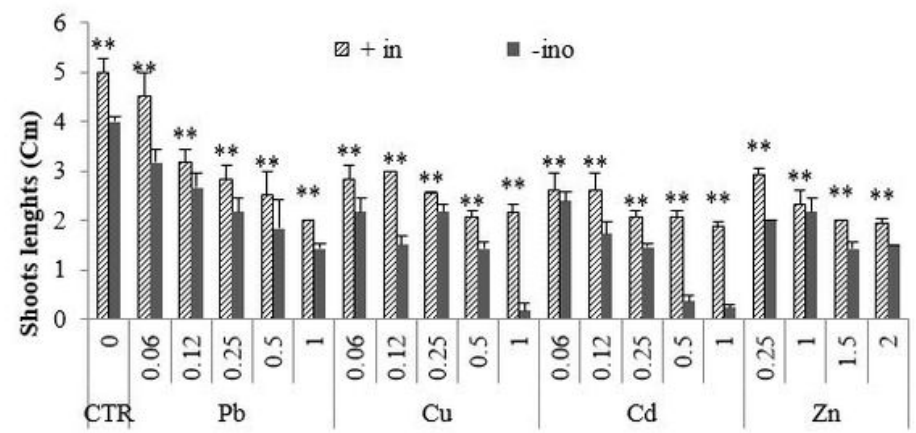

Metallic concentrations (mM)

Figure 1

Effect of PGPR inoculation on roots and shoots length of Lactuca sativa $(a, b)$ and Peganum harmala (c, d) seedlings after two weeks of growth under different concentrations of heavy metals. Results are expressed as mean \pm SD $(n=3)$.ns: not significant, ** Significantly different than respective uninoculated control according to Student's t test $(p<0.01)$. +lnc: with bacterial inoculation; -Inc: without bacterial inoculation.
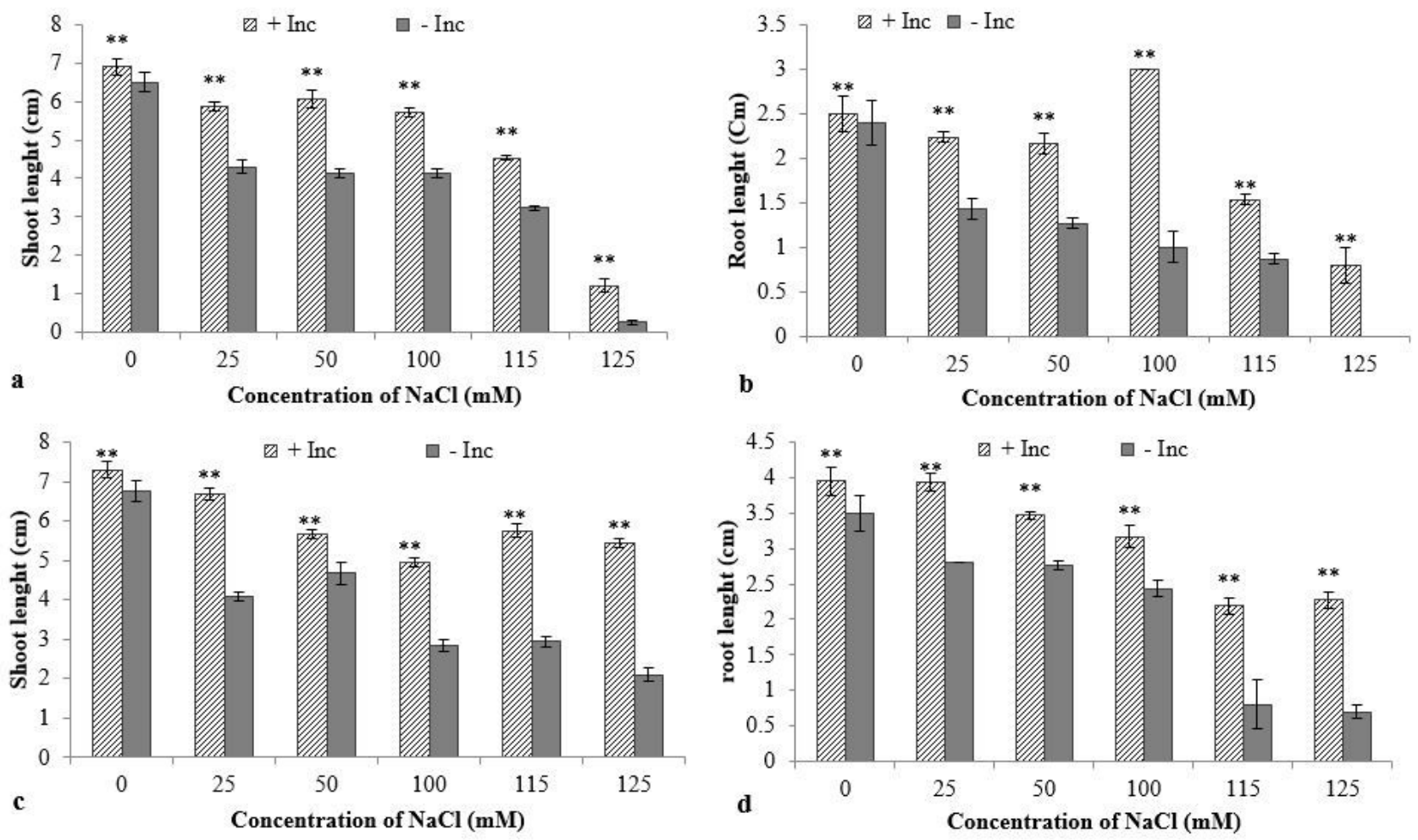

Figure 2 
Effect of PGPR inoculation on growth parameters of Lactuca sativa (a and b) and Peganum harmala (c and d) seedlings grown under different concentrations of $\mathrm{NaCl}$. Results are expressed as mean $\pm \mathrm{SD}(\mathrm{n}=3)$. ns: not significant, ** Significantly different than respective uninoculated control according to Student's t test $(\mathrm{p}<0.01)$. Inc, with bacterial inoculation; - Inc, without bacterial inoculation.
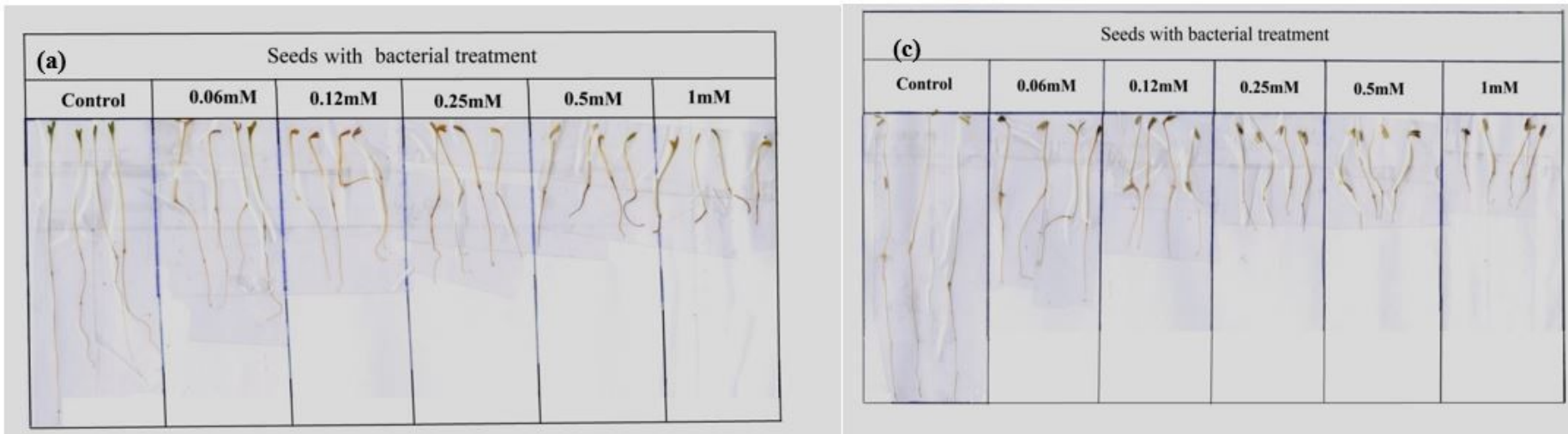

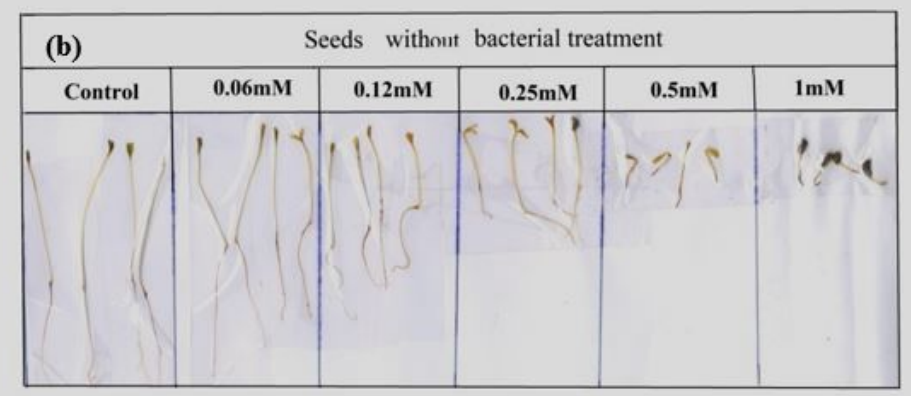

\begin{tabular}{|c|c|c|c|c|c|}
\hline \multicolumn{6}{|c|}{ Seeds without bacterial treatment } \\
\hline Control & $0.06 \mathrm{mM}$ & $0.12 \mathrm{mM}$ & $0.25 \mathrm{mM}$ & $0.5 \mathrm{mM}$ & $1 \mathrm{mM}$ \\
\hline 4 & 7101 & $7>$ & 19 & lian & Wes \\
\hline$i^{\prime}$ & & & & & \\
\hline & & & & & \\
\hline & & & & & \\
\hline
\end{tabular}

\section{Figure 3}

Effect of PGPR inoculation on root and shoots elongation of Peganum harmala ( $a$ and $b$ ) and Lactuca sativa (c and d) after two weeks of incubation under different concentration of $\mathrm{Cd}$

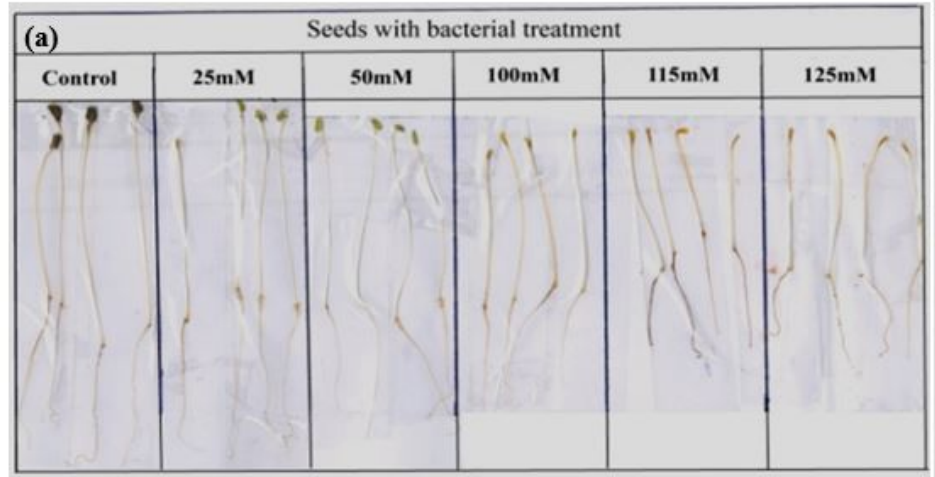

\begin{tabular}{|l|l|l|l|l|l|l|}
\hline (c) & \multicolumn{7}{|c|}{ Seeds with bacterial treatment } \\
\hline Control & $25 \mathrm{mM}$ & $50 \mathrm{mM}$ & $100 \mathrm{mM}$ & $115 \mathrm{mM}$ & $125 \mathrm{mM}$ \\
\hline & & & & & & \\
\hline
\end{tabular}

Figure 4 
Effect of PGPR inoculation on root and shoots elongation of Peganum harmala (a and b) and Lactuca sativa (c and d) after two weeks of incubation under different concentration of $\mathrm{NaCl}$

Page $21 / 21$ 